\title{
Interplay of IKK/NF-KB signaling in macrophages and myofibers promotes muscle degeneration in Duchenne muscular dystrophy
}

\author{
Swarnali Acharyya, ${ }^{1,2}$ S. Armando Villalta, ${ }^{3}$ Nadine Bakkar, ${ }^{1,2}$ Tepmanas Bupha-Intr, ${ }^{4}$ \\ Paul M.L. Janssen, ${ }^{4}$ Micheal Carathers, ${ }^{1}$ Zhi-Wei Li, ${ }^{5}$ Amer A. Beg, ${ }^{5}$ Sankar Ghosh, ${ }^{6}$ \\ Zarife Sahenk, ${ }^{7}$ Michael Weinstein, ${ }^{1,8}$ Katherine L. Gardner, ${ }^{9}$ Jill A. Rafael-Fortney, ${ }^{9}$ \\ Michael Karin, ${ }^{10}$ James G. Tidball, ${ }^{3}$ Albert S. Baldwin, ${ }^{11}$ and Denis C. Guttridge ${ }^{1,2,12}$
}

\begin{abstract}
${ }^{1}$ Human Cancer Genetics Program and ${ }^{2}$ Department of Molecular Virology, Immunology and Medical Genetics, The Ohio State University College of Medicine, Columbus, Ohio, USA. ${ }^{3}$ Department of Physiological Science, UCLA, Los Angeles, California, USA. ${ }^{4}$ Department of Physiology and Cell Biology, The Ohio State University College of Medicine, Columbus, Ohio, USA. 5H. Lee Moffitt Cancer Center and Research Institute, University of South Florida, Tampa, Florida, USA. ${ }^{6}$ Department of Molecular Biophysics and Biochemistry, Yale University, New Haven, Connecticut, USA. ${ }^{7}$ Columbus Children's Research Institute, Columbus, Ohio, USA. ${ }^{8}$ Department of Molecular Genetics and ${ }^{9}$ Department of Molecular and Cellular Biochemistry, The Ohio State University College of Medicine, Columbus, Ohio, USA. ${ }^{10}$ Department of Pharmacology, UCSD, San Diego, California, USA. ${ }^{11}$ University of North Carolina at Chapel Hill and TheraLogics Inc., Research Triangle Park, North Carolina, USA. 12The Ohio State University Comprehensive Cancer Center - Arthur G. James Cancer Hospital and Solove Research Institute, Columbus, Ohio, USA.
\end{abstract}

\begin{abstract}
Duchenne muscular dystrophy (DMD) is a lethal X-linked disorder associated with dystrophin deficiency that results in chronic inflammation and severe skeletal muscle degeneration. In DMD mouse models and patients, we find that I $\kappa B$ kinase/NF- $\kappa B$ (IKK/NF- $\kappa B$ ) signaling is persistently elevated in immune cells and regenerative muscle fibers. Ablation of 1 allele of the $\mathrm{p} 65$ subunit of NF- $\mathrm{kB}$ was sufficient to improve pathology in $m d x$ mice, a model of DMD. In addition, conditional deletion of IKK $\beta$ in $m d x$ mice elucidated that NF- $\mathrm{B}$ functions in activated macrophages to promote inflammation and muscle necrosis and in skeletal muscle fibers to limit regeneration through the inhibition of muscle progenitor cells. Furthermore, specific pharmacological inhibition of IKK resulted in improved pathology and muscle function in $m d x$ mice. Collectively, these results underscore the critical role of NF- $\kappa B$ in the progression of muscular dystrophy and suggest the IKK/NF- $\mathrm{K}$ signaling pathway as a potential therapeutic target for DMD.
\end{abstract}

\section{Introduction}

Duchenne muscular dystrophy (DMD) is the most common lethal $\mathrm{X}$-linked recessive disorder, affecting 1 in 3,500 live male births (1). DMD children show early symptoms of muscle degeneration, frequently develop contractures, and lose the ability to walk between 6 and 12 years of age. With progressive disease, most patients succumb to death from respiratory failure and cardiac dysfunction in their twenties (2). The primary cause of this disease stems from mutations in the dystrophin gene, which is essential for the structural and functional integrity of muscles (3). Dystrophin interacts with several members of the dystrophin glycoprotein complex, which forms a mechanical as well as signaling link from the extracellular matrix to the cytoskeleton (4). Mutations in dystrophin result in membrane damage, allowing massive infiltration of immune cells, chronic inflammation, necrosis, and severe muscle degeneration (2). Normally, muscle cells possess the capacity to regenerate in response to injury signals. However, this ability is lost

Nonstandard abbreviations used: CLN, centrally located nuclei; DKO, double KO; DMD, Duchenne muscular dystrophy; E-MyHC, embryonic myosin heavy chain; IKK, IאB kinase; LGMD, limb-girdle muscular dystrophy; MCP-1 $\alpha$, monocyte chemoattractant protein-1 $\alpha$; MLC, myosin light chain; NBD, NEMO-binding domain; TA, tibialis anterior

Conflict of interest: A.S. Baldwin and S. Ghosh declare equity positions in TheraLogics Inc.

Citation for this article: J. Clin. Invest. 117:889-901 (2007). doi:10.1172/JCI30556. in DMD, presumably due to an exhaustion of satellite cells during ongoing degeneration and regeneration cycles (1). Although dystrophin mutations represent the primary cause of DMD, it is the secondary processes involving persistent inflammation and impaired regeneration that likely exacerbate disease progression.

The microenvironment of dystrophic muscles consists of elevated numbers of inflammatory cells that act as a complex interface for cytokine signaling $(5,6)$. In particular, TNF- $\alpha$ levels are upregulated in dystrophic muscles from animal models and DMD patients $(7,8)$. Among its pleiotropic effects, TNF- $\alpha$ acts as a potent inducer of the inflammatory response transcription factor NF- $\kappa B(9,10)$. In mammalian cells, NF- $\kappa B$ consists of 5 members, RelA (p65), RelB, c-Rel, p50, and p52, of which p50/p65 is the most prototypical NF- $\kappa \mathrm{B}$ complex found in cells. In inactive conditions, $\mathrm{NF}-\kappa \mathrm{B}$ is mostly retained in the cytoplasm through binding of the

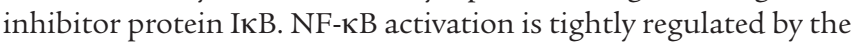
IКB kinase (IKK) complex composed of catalytic subunits, IKK $\alpha$ and IKK $\beta$, and a regulatory subunit, IKK $\gamma /$ NEMO (11). Classical stimulatory signals such as proinflammatory cytokines result in IKK $\beta$-mediated site-specific phosphorylation and subsequent deg-

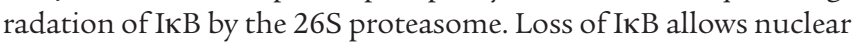
$\mathrm{NF}-\kappa \mathrm{B}$ accumulation and subsequent transcription of diverse genes encoding growth factors, cytokines, chemokines, antiapoptotic proteins, and cell adhesion molecules (12). In addition to this classical activation mechanism by IкB degradation, posttransla- 


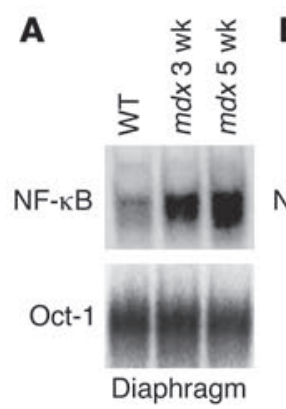

E

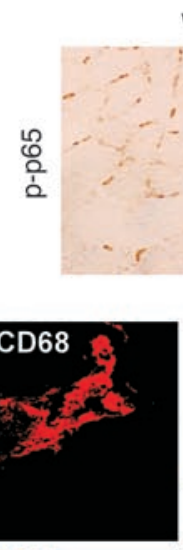

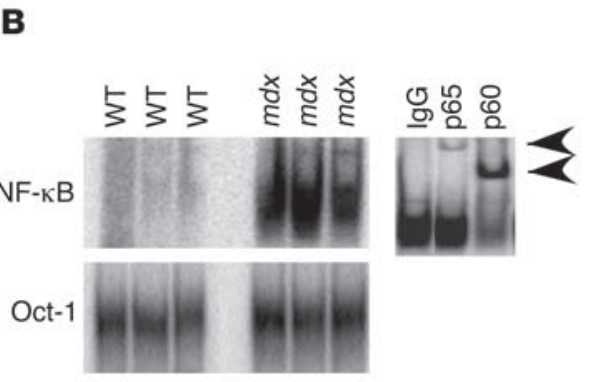

TA
C

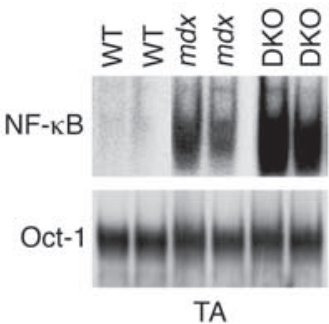

TA

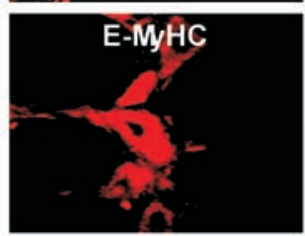

F
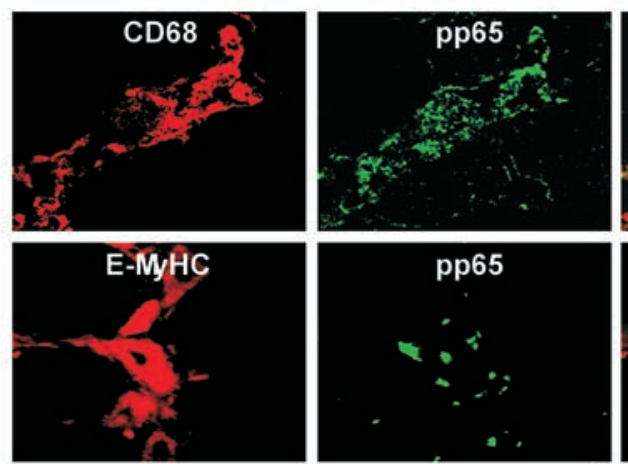

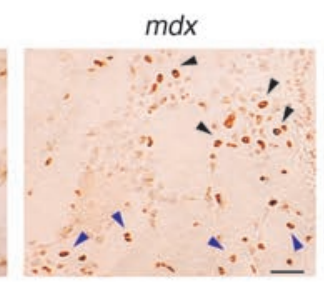

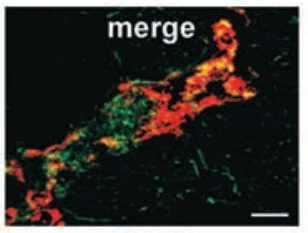

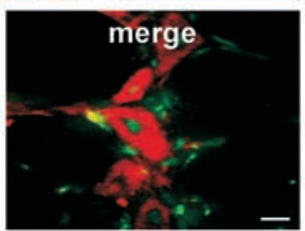

G
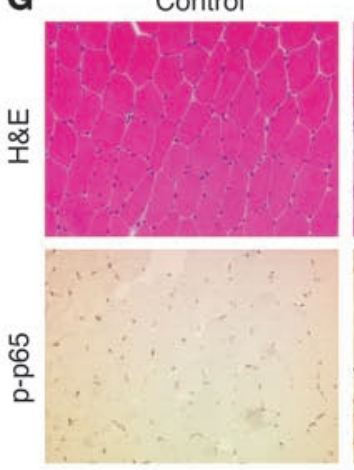

p-IKK

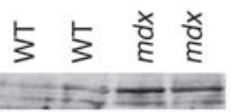

GST-IkB $\alpha$ (WT) GST-IKB $\alpha(\mathrm{SS} / \mathrm{TT})$

$\mathrm{p}-\mathrm{I \kappa} \mathrm{B} \alpha$

IкB $\alpha$

GST-p65 (WT)

GST-p65 (S/A)

p-p65

p65

Ikk $\gamma$

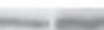

Figure 1

NF-kB activity in dystrophic muscle is localized to both muscle and immune cells. (A-C) Muscle nuclear extracts from 5-week-old WT C57BL/10 and 3- and 5-week-old $m d x$ mice (A), 5-week-old WT and $m d x$ mice (B), or 7-week-old WT, $m d x$, and DKO mice (C) were used in EMSA for NF-KB and Oct-1. Supershift assays were performed on $m d x$ muscle extracts using antibodies against p65 and p50. Arrowheads denote shifted subunits. (D) IKK assays performed with IKB $\alpha$ WT and mutant (double serine to threonine [SS/TT]) or p65 WT and mutant (serine to alanine [S/A]) substrates using gastrocnemius muscle lysates from 7-week-old WT or $m d x$ mice. Immunoprecipitates were probed for IKK $\gamma$ as a loading control. Western blots are shown for $\mathrm{p}-\mathrm{IKK}, \mathrm{p}-\mathrm{I} \mathrm{KB} \alpha, \mathrm{I} \mathrm{KB} \alpha, \mathrm{p}-\mathrm{p} 65$, and $\mathrm{p} 65$. GST, glutathione-S-transferase. (E) Gastrocnemius muscles from 7-week-old WT or $m d x$ mice were immunostained for p-p65. Scale bars: 50 um. Black arrowheads denote immune cells, and blue arrowheads indicate regenerating fibers. (F) Muscles from either 4- or 7-week-old $m d x$ mice were double stained with p-p65 (green) and CD68 (red) or p-p65 and E-MyHC (red), respectively. Scale bars: $20 \mu \mathrm{m}$. (G) H\&E staining and p-p65 immunohistochemistry were performed on muscle biopsies from healthy controls and age-matched DMD patients $(n=4)$. Scale bar: $50 \mu \mathrm{m}$.

tional modifications of $\mathrm{p} 65$ by phosphorylation, acetylation, and ubiquitination have been shown to modulate the transactivation

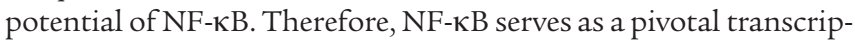
tion factor with multiple levels of regulation that mediates a host of biological functions (9). Furthermore, chronic activation of $\mathrm{NF}-\kappa \mathrm{B}$ is frequently associated with pathophysiological states of cancer, rheumatoid arthritis, sepsis, and asthma $(9,13)$.

Evidence of perturbation of NF- $\mathrm{\kappa B}$ signaling also exists in conditions of muscle atrophy $(14,15)$ and in dystrophies such as limb-girdle muscular dystrophy (LGMD) and DMD $(16,17)$. While NF-KB cell survival function is repressed in LGMD, NF-KB signaling is instead persistently activated in dystrophinopathies. However, relatively little is known about the mechanisms of action or regulation of NF- $\mathrm{KB}$ signaling in these muscular dystrophies. Moreover, the nature and origin of NF-KB activity in DMD patients has also not been resolved. In this study, we use genetic analysis of dystrophin- deficient mice to elucidate the dual contribution of IKK/NF- $\mathrm{KB}$ signaling originating in immune cells and that originating in skeletal muscle fibers in promoting dystrophic pathology. Furthermore, we show that inflammation is decreased and regeneration enhanced following selective pharmacological inhibition of IKK, implicating IKK/NF- $\mathrm{KB}$ as a suitable therapeutic target in DMD.

\section{Results}

$N F-\kappa B$ is activated in immune cells and myofibers of dystrophic muscles. In order to gain insight into NF-kB regulation in muscular dystrophy, we performed EMSA analysis on dystrophic muscles from $m d x$ mice, a widely used mouse model of $\operatorname{DMD}(3,4)$. In line with previous findings (18), NF-KB DNA binding activity was found to be significantly higher in diaphragm muscles from $m d x$ mice compared with C57BL/10 controls (Figure 1A), but importantly, a similar profile was also observed in tibialis anterior (TA) and gas- 


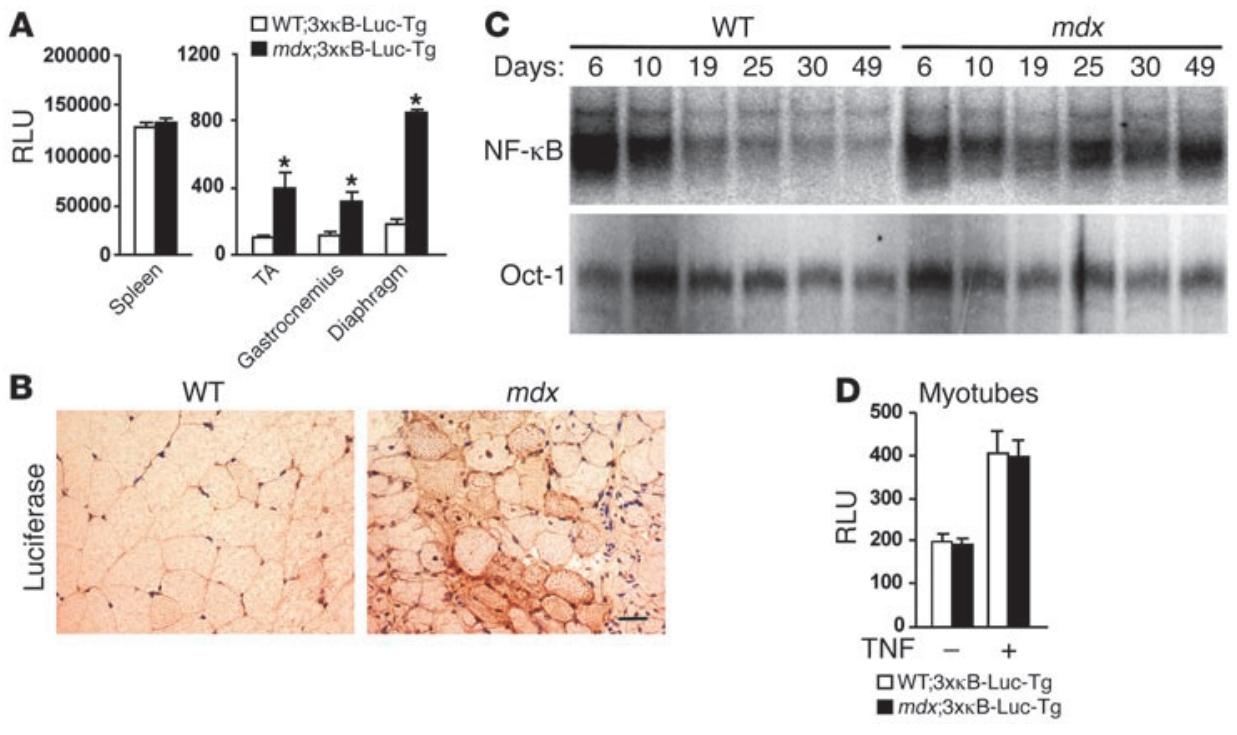

Figure 2

$\mathrm{NF}-\mathrm{\kappa B}$ activity is deregulated during postnatal development of $m d x$ mice. (A) Muscle extracts from 5-week-old WT;3хкB-Luc-Tg or $m d x ; 3 \times \kappa B-L u c-T g$ mice were prepared for luciferase assays. Luciferase values were normalized to total protein. ${ }^{*} P<0.05 ; n=5$. (B) Gastrocnemius muscles were immunostained for luciferase expression in 7-week-old WT;3хкB-Luc-Tg and $m d x ; 3 \times \kappa B$-Luc-Tg mice $(n=3)$. Scale bar: $50 \mu \mathrm{m}$. (C) EMSAs for NF-kB and Oct-1 performed in gastrocnemius muscles from WT and $m d x$ mice during postnatal development. (D) Primary myoblasts isolated from 6-day-old WT;3хк-Luc-Tg and $m d x ; 3 \times \kappa B$-Luc-Tg mice were differentiated and subsequently switched to either medium alone or medium containing TNF- $\alpha(5 \mathrm{ng} / \mathrm{ml})$ for 6 hours.

trocnemius muscles (Figure 1B and Supplemental Figure 1A; supplemental material available online with this article; doi:10.1172/ JCI30556DS1). Since diaphragm represents the most affected $m d x$ muscle (1), these results suggested that NF- $\mathrm{\kappa B}$ activity positively correlated with degeneration but did not discriminate between the degree of muscle loss in different muscle groups. Supershift EMSAs revealed the binding contribution of both p50 and p 65 subunits of NF-кB (Figure 1B), but in contrast to past findings (18) we found that this activity derived mainly from p50 and less from p65. In addition, little to no binding occurred as a result of contributions of the subunits c-Rel, RelB, p52, or Bcl-3 (data not shown). Furthermore, NF- $\mathrm{KB}$ activity correlated strongly with disease severity, since considerably higher NF- $\mathrm{BB}$ binding was associated with muscles from utrophin-dystrophin double KO (DKO) mice (19), which, compared with $m d x$ mice, more closely recapitulate the clinical signs and early lethality of DMD patients (Figure 1C).

Consistent with NF-KB binding, IKK activity as determined by Western blotting and GST-IкB $\alpha$ phosphorylation was also considerably higher in $m d x$ muscles (Figure 1D). However, unlike clas-

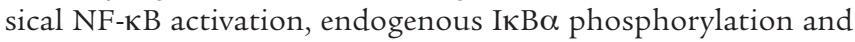
degradation were not associated with this dystrophic phenotype, a finding that was further confirmed using sucrose density-purified cytosolic fractions (Figure 1D and data not shown). Nevertheless, we were able to clearly detect the endogenous phosphorylated form of p65 at serine residue 536 (p-p65), and kinase assays supported that p65 at serine 536 is a competent substrate for IKK phosphorylation in $m d x$ muscles. These findings are in line with the recent notion that $\mathrm{p} 65$ activation by IKK $\beta$ may occur independently of classical IKB degradation (20). Further immunohistochemical analysis of $m d x$ muscles revealed increases in the phosphorylated (Figure 1E) but not total form of p65 (Supplemental Figure 1B).
To determine whether increases in NF-кB DNA binding and phosphorylation translated to transcriptional activity, we utilized transgenic NF-кB-luciferase reporter mice (21) (3хкB-Luc-Tg mice) that were crossed into an $m d x$ background. Results showed that luciferase activity significantly increased only in dystrophic muscles and not in unaffected spleen, liver, or kidney (Figure 2A and data not shown). Immunohistochemical analysis with luciferase also supported the results shown above indicating that NF-кB activity derived from both regenerating fibers and immune cells (Figure 2B). Interestingly, in using reporter mice, we discovered that WT neonates contained a relatively high level of skeletal muscle-specific NF-кB activity that diminished over the following weeks of postnatal development, a finding that was confirmed by classical EMSA analysis (Figure 2C). In $m d x$ muscles, NF-кB activity also appeared to diminish within the first few weeks but subsequently became reactivated and persisted over time. We suspect that this maintenance in activity derives from proinflammatory or cellular damage-associated factors that begin to accumulate at around the time when levels of NF- $\mathrm{KB}$ in unaffected muscles would normally begin to decline. These in vivo results also indicated that the inherent loss of dystrophin itself is not sufficient to activate NF-кB. To further examine this point, we determined NF- $\kappa \mathrm{B}$ determined using primary myotube cultures. Results showed that basal and TNF-induced NF- $\kappa B$ transcriptional activities were similar in myotubes isolated from WT and $m d x 3 \times$ хкBLuc-Tg reporter mice (Figure 2D), as were NF-кB DNA binding activities of control, $m d x$, or DKO myotubes (data not shown). This argues that regulation of IKK/NF-KB signaling in dystrophic muscle occurs secondarily to the loss of dystrophin expression.

Heterozygous deletion of the $p 65$ subunit improves dystrophic pathology. In order to define the role of NF- $\mathrm{BB}$ in the dystrophic process, we used 

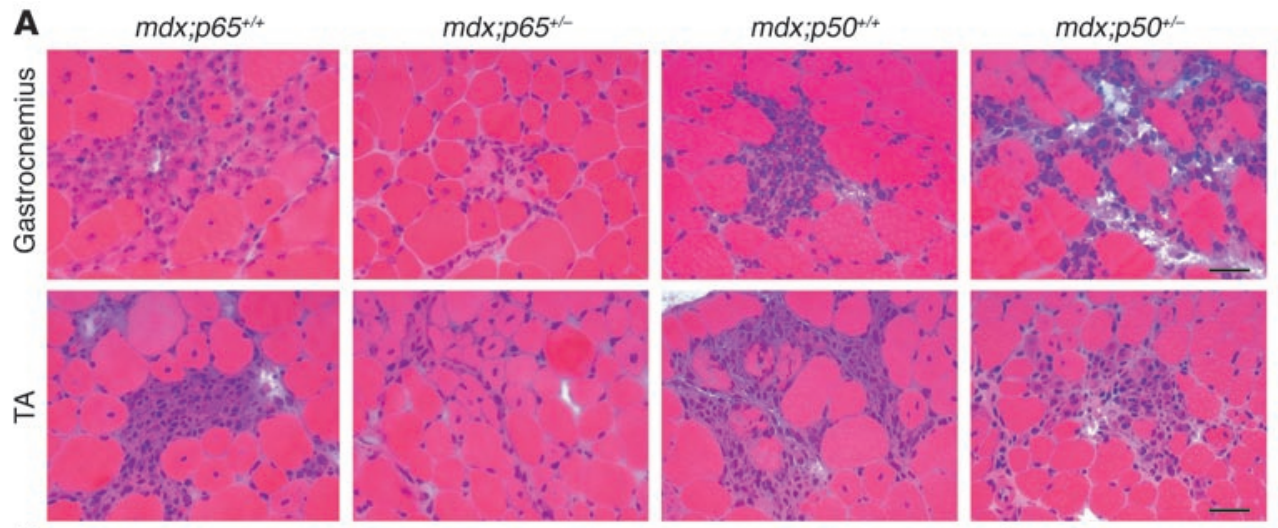

B

WT

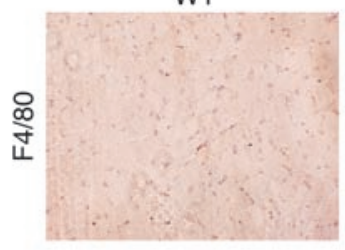

D

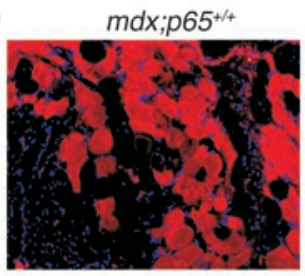

$m d x ; p 65^{+/+}$

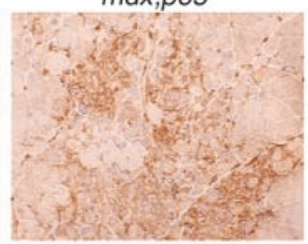

$m d x ; p 65^{+/}$

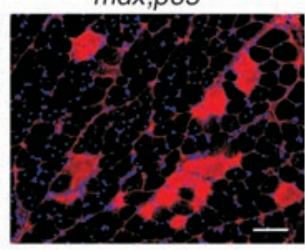

$m d x ; p 65^{+-}$
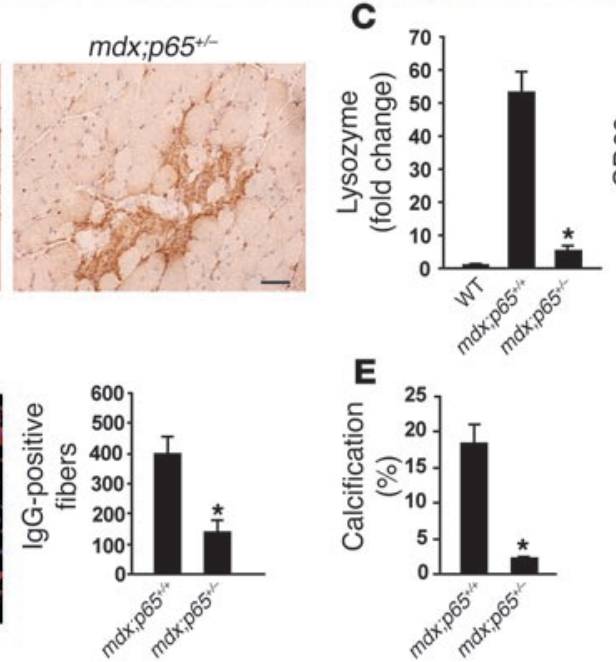

Figure 3

Heterozygous deletion of p65 rescues $m d x$ pathology. (A) Histopathology of muscle cryosections stained with H\&E, comparing 5-week-old $m d x ; p 65^{+/+}$and $m d x ; p 65^{+/-}$mice or $m d x ; p 50^{+/+}$and $m d x ; p 50^{+/-}$mice. Scale bars: $20 \mu \mathrm{m}$. (B) Gastrocnemius sections from WT C57BL/10, $m d x ; p 65^{+/+}$, and $m d x ; p 65^{+/-}$mice were immunostained with F4/80. Scale bar: $50 \mu \mathrm{m}$. (C) RNA was isolated from the remaining part of the

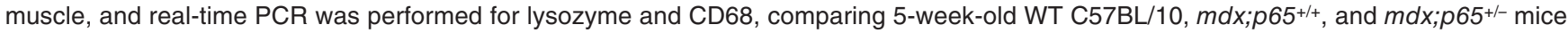
$(n=3)$. (D) Necrotic fibers from gastrocnemius muscles were quantitated based on IgG staining (filled fibers appear in red, nuclei in blue) $(n=5)$. Scale bar: $100 \mu \mathrm{m}$. (E) Calcifications were quantitated from $m d x ; p 65^{+/+}$and $m d x ; p 65^{+/-}$muscles $(n=10)$. Data are plotted as mean \pm SEM from 2 independent experiments. ${ }^{*} P<0.05$.

mice deficient in p 65 or p50 subunits $(22,23)$. Since homozygous deletion of p65 results in embryonic lethality that can be rescued with further ablation of TNFa (24), triple p65, TNF- $\alpha$, and dystrophin KOs were generated by crossing $p 65^{+/-} \mathrm{TNFa}^{-/-}$mice with $m d x$ animals. Consistent with previous reports (25), we found that deletion of TNFa alone resulted in an exacerbated dystrophic pathology in an $m d x$ background (data not shown), thereby limiting the ability to examine dystrophic muscle in the complete absence of this NF-кB subunit. Due to this limitation, p65 heterozygous mice crossed into an $m d x$ background were instead used and compared with $m d x$ p 65 WT littermates. Histological analysis showed that muscle pathology was notably improved in $m d x ; p 65^{+--}$but not $m d x ; p 50^{+/-}$mice (Figure $3 \mathrm{~A}$ ). Examination of $m d x ; p 50^{+/-}$muscles revealed a predicted reduction in p50 DNA binding, and interestingly, compensatory binding of p50 occurred in muscles lacking p65 (Supplemental Figure 2A). Therefore, although p50 DNA binding activity in our hands was found to predominate NF- $\kappa B$ complexes in $m d x$ muscles, this activity does not appear to influence disease, suggesting that dystrophic pathology is selectively regulated by 65 .
We next sought to determine the mechanisms by which p65 mediates its action on dystrophic muscles. Since macrophages represent a major compartment of immune cells in dystrophinopathies $(6,26)$, muscles were stained with the F4/80 macrophage marker. Immunohistochemical analysis showed a marked reduction in macrophage infiltrates in the necrotic phase in $m d x ; p 65^{+/-}$mice compared with $m d x ; p 65^{+/+}$littermates (Figure 3B), which was consistent with the associated $90 \%$ and $86 \%$ mean reduction $(P<0.01)$ in additional macrophage markers, lysozyme and CD68, respectively (Figure 3C). Decreased macrophage invasion in $m d x ; p 65^{+/-}$mice also correlated with a $65 \%$ $(P=0.002)$ reduction in necrosis as determined by quantification of IgG positive-stained fibers (Figure 3D), while similar decreases in macrophage infiltration or necrosis were not observed in $m d x ; p 50^{+/-}$mice (Supplemental Figure 2, B and C, and data not shown). Another hallmark of $m d x$ muscle degeneration is the calcification deposits resulting from abnormal calcium influx or intracellular release (1). Similar to the decrease in inflammation, $m d x ; p 65^{+/-}$mice exhibited an $88 \%$ reduction $(P=0.008)$ in 
A

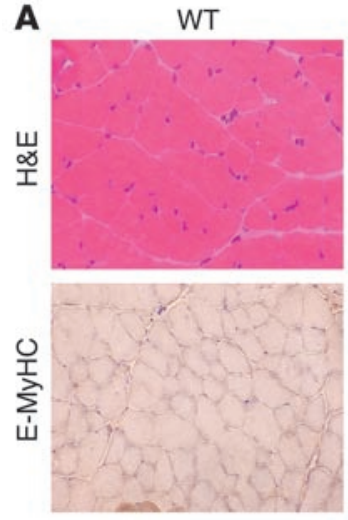

D

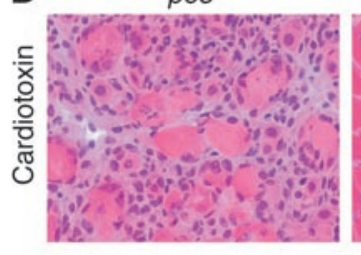

$m d x ; p 65^{+/+}$

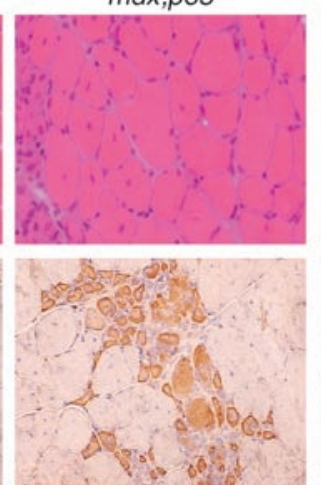

p65

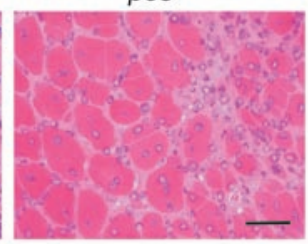

$m d x ; p 65^{+-}$

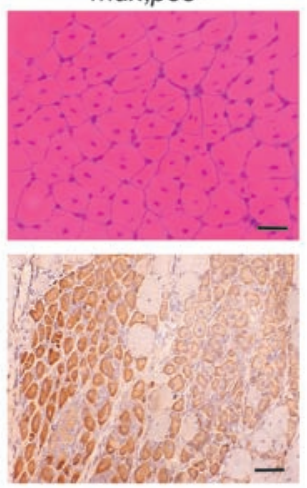

E

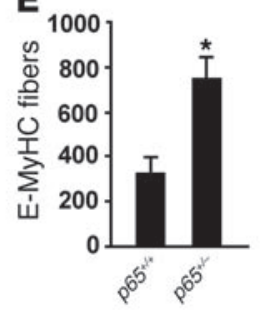

B
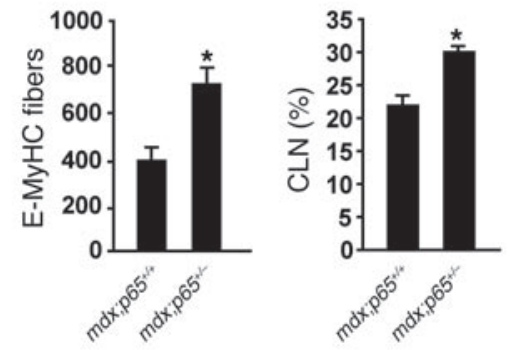

\section{Figure 4}

Heterozygous deletion of p65 promotes regenerative myogenesis in $m d x$ mice. (A) Gastrocnemius cryosections from 7-week-old $m d x ; p 65^{+/+}$ and $m d x ; p 65^{+/-}$male mice were stained with H\&E (top row) or immunostained for E-MyHC (bottom row). Scale bars: $15 \mu \mathrm{m}$ (top) and $50 \mu \mathrm{m}$ (bottom). (B and C) Quantitation of E-MyHC-positive fibers and CLN. (D and E) TA sections from 5-week-old cardiotoxin-treated p65+/+ and $p 65^{+/-}$mice were stained with H\&E, and numbers of E-MyHC fibers were calculated. Scale bar: $20 \mu \mathrm{m}$. Data are plotted as mean \pm SEM from 2 independent experiments $(n=4) .{ }^{*} P<0.05$.

calcification compared with $m d x ; p 65^{+/+}$littermates (Figure 3E). However, we were unable to detect reexpression of dystrophinassociated complex proteins (Supplemental Figure 2D), which shows that blocking p65 activity is not sufficient to restore the primary dystrophin deficiency present in these muscle fibers.

In response to the ongoing phases of degeneration in dystrophic muscles, cycles of regeneration attempt to compensate for the loss of muscle mass. However, this process soon ceases in DMD patients due to exhausted regenerative potential resulting from premature senescence of satellite cells and accelerated attrition in telomeres (1). Interestingly, we observed by both $\mathrm{H} \& \mathrm{E}$ and $\mathrm{E}-\mathrm{MyHC}$ analysis that $m d x ; p 65^{+-}$muscles contained higher numbers of regenerating fibers compared with $m d x ; p 65^{+/+}$mice (Figure 4A). Scoring for E-MyHC-positive stained fibers revealed a mean increase of $43 \%$ in $m d x ; p 65^{+/-}$muscles $(721.2 \pm 90.2)$ over that of muscles from $m d x ; p 65^{+/+}$mice $(409.2 \pm 77.8 ; P=0.0008)$ (Figure 4B). In addition, the percentage of centrally located nuclei (CLN) was also found to be significantly higher in $m d x ; p 65^{+/-}(30.05 \pm 1.02)$ than $m d x ; p 65^{+/+}$ muscles $(21.89 \pm 1.68 ; P=0.0002)$ (Figure $4 \mathrm{C})$. To further examine NF- $\kappa \mathrm{B}$ regulation of injury-induced secondary myogenesis, we utilized the well-established cardiotoxin regeneration model (27). Consistent with $m d x$ analysis, muscle sections from $p 65^{+/-}$mice 6 days after cardiotoxin injection showed reduced inflammation that was associated with a significant increase in E-MyHC-positive fibers $(P=0.0002)$ (Figure 4, D and E).

Myeloid deletion of IKK $\beta$ reduces inflammation and necrosis in dystrophic muscles. It is generally accepted that muscle regeneration occurs in response to injury and inflammation and that modulation of this inflammatory process would predictably decrease, rather than increase, the regeneration capacity of skeletal muscle as we had observed in $m d x ; p 65^{+/-}$mice. One explanation for these results is that in addition to its more accepted role as a regulator of immune response, activation of NF- $\mathrm{\kappa B}$ might also function in skeletal muscle as a negative regulator of myogenesis (28). In order to decipher these potential cellular functions of NF- $\mathrm{KB}$ in dystrophic muscle, we utilized IKK $\beta$ conditional KO mice (29). Myeloidspecific lysozyme-driven Cre transgenic mice (Lys-Cre mice) (30) were therefore crossed with $m d x ; I K K \beta^{F / F}$ (flox/flox) animals, and resulting $m d x ; I K K \beta^{F / F} ;$ Lys-Cre offspring were obtained in expected Mendelian ratios. Due to a predominant ratio of muscle fibers to macrophages in dystrophic muscle, selective deletion of IKK $\beta$ from the immune cell compartment was undetectable by standard Western blot analysis (data not shown), but such reduction was observed by CD68/IKK $\beta$ coimmunofluorescence staining (Figure 5A). Consistent with the findings that IKK $\beta$ may be directly linked to p 65 phosphorylation and NF- $\mathrm{\kappa B}$ activity (31), reduction in IKK $\beta$ levels resulted in a decrease in p-p65 signaling in immune cells but not regenerating muscle cells (Figure 5B). In connection to the reduction in IKK/NF- $\mathrm{KB}$ signaling, muscle pathology was noticeably improved in $m d x ; I K K \beta^{F / F} ;$ Lys-Cre mice, which had a $51 \%$ decrease $(P=0.0019)$ in necrotic patches compared with $m d x ; I K K \beta^{F / F}$ controls (Figure 5C). Nevertheless, no significant differences in CD68 expression were detected (Figure 5D), suggesting that IKK $\beta$ activity in macrophages is not required for the recruitment of these cells to a dystrophin-deficient muscle. However, since cytokines and chemokines contribute to a dystrophic pathology (8), we hypothesized that deletion of IKK $\beta$ in the immune cell compartment might result in a reduction in the overall inflammation burden in these 
A
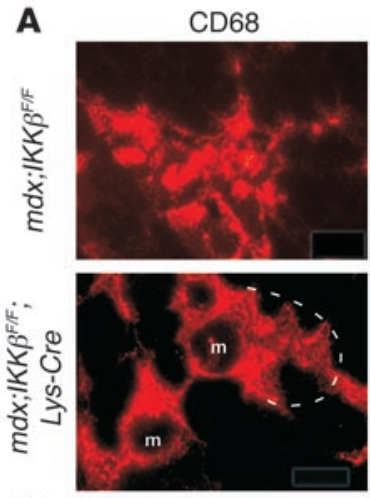

C
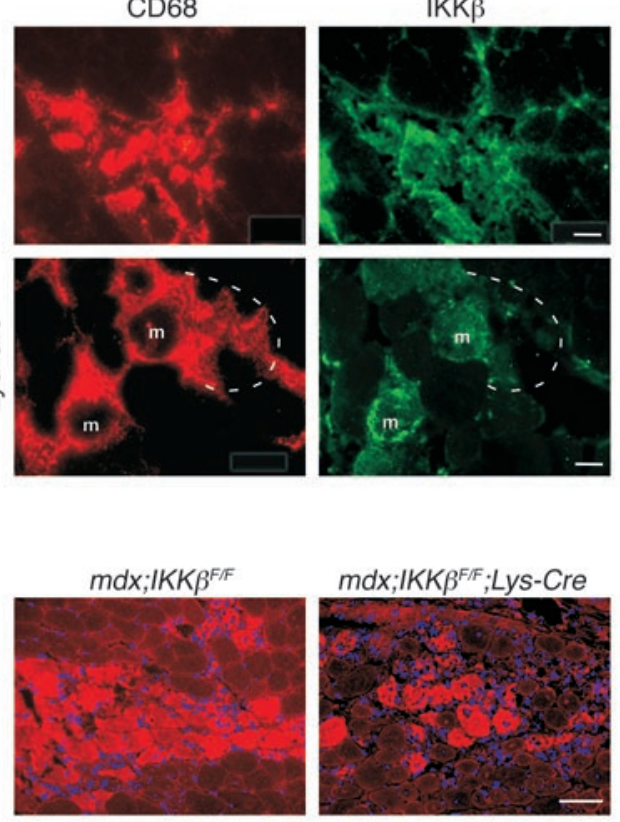

$\mathbf{E}$

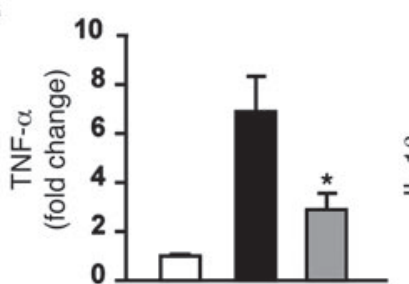

B
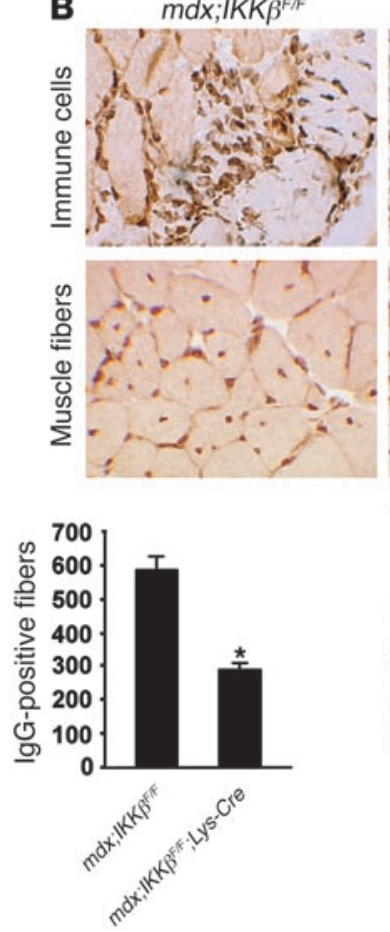

$m d x ; I K K \beta^{F / F} ;$ Lys-Cre
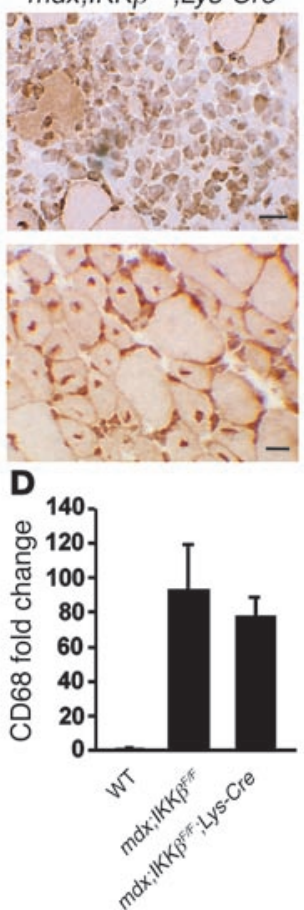

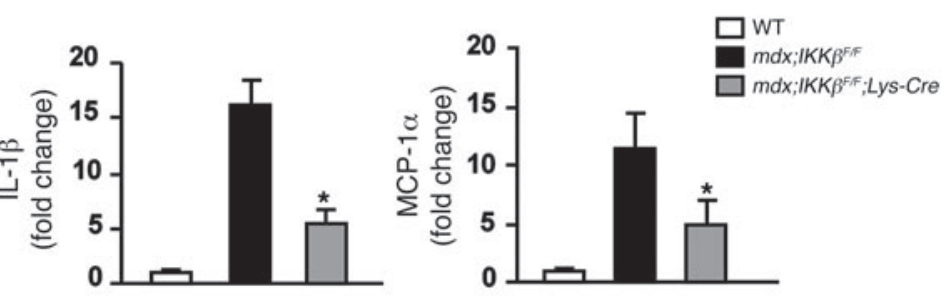

Figure 5

IKK $\beta$ deletion in myeloid cells reduces inflammation. (A and $\mathbf{B}$ ) Gastrocnemius sections from 4-week-old $m d x ; I K K \beta \beta^{F / F}$ and $m d x ; / K K \beta F / F ; L y s$-Cre male mice were analyzed either by double immunofluorescence staining against IKK $\beta$ (green) and CD68 (red) (A) or by immunohistochemistry for p-p65 (B). Dashed white lines in A mark field of macrophages. m, muscle fibers. Scale bars: $10 \mu \mathrm{m}$. (B) p-p65 immunohistochemical staining of immune infiltrates (top row) and regenerating muscle fibers (bottom row). Scale bars: $15 \mu \mathrm{m}$ (top) and $10 \mu \mathrm{m}$ (bottom). (C) Necrotic fibers were identified by IgG staining (filled fibers in red, nuclei in blue) $(n=6)$. Scale bar: $50 \mu \mathrm{m}$. Quantification of necrosis appears in the graph. (D) Real-time PCR analysis of CD68 in TA from sex- and age-matched WT, $m d x ; I K K \beta^{F / F}$ and $m d x ; I K K \beta^{F / F}$; Lys-Cre mice. (E) Real-time PCR analysis was performed as described in $\mathbf{D}$ for TNF- $\alpha$, IL-1 $\beta$, and MCP-1. Graphs are plotted as mean \pm SEM. ${ }^{*} P<0.05$.

diseased muscles. Indeed, by real-time PCR analysis, we observed decreases in TNF- $\alpha$ (58\%; $P=0.011)$, IL- $1 \beta(66 \% ; P=0.002)$, and monocyte chemoattractant protein-1 $\alpha / \mathrm{CC}$ chemokine ligand 2 (MCP-1 $\alpha /$ CCL2) $(45 \% ; P=0.030)$ in $m d x ; I K K \beta^{F / F} ;$ Lys-Cre muscles compared with $m d x ; I K K \beta^{F / F}$ controls (Figure $5 \mathrm{E}$ ). Interestingly, as shown in Figure 5B, this reduction in proinflammatory cytokines did not affect the activated state of $\mathrm{p} 65$ originating in muscle fibers from $m d x ; I K K \beta^{F / F}$;Lys-Cre mice, suggesting that other mediators in addition to TNF- $\alpha$ and IL- $1 \beta$ contribute to the persistent activation of NF-KB in dystrophic muscle. Moreover, quantitation analysis of E-MyHC staining revealed that there were no significant differences in the number of regenerating fibers between these groups of mice (data not shown), further suggesting that the primary role of IKK $\beta / \mathrm{NF}-\kappa \mathrm{B}$ signaling in recruited macrophages is to promote the proinflammatory network leading to muscle necrosis.

Myofiber-specific deletion of IKK $\beta$ promotes regeneration in dystrophic muscles. Having gained insight into the role of NF-кB signaling in the immune cell compartment of dystrophin-deficient muscle, we now turned our attention to the requirement of this signaling pathway in skeletal muscle fibers. For this analysis, $m d x ; I K K^{F / F}$ mice were crossed with Cre knock-in mice under the regulation of the myosin light chain 1f promoter (MLC-Cre mice), whose expression has been shown to be highly restricted to skeletal muscles (32). Surprisingly, genotyping analysis from more than 100 progeny showed that MLC-Cre animals, in contrast to myeloid-depleted IKK $\beta$ mice, were not obtained in the expected Mendelian ratios, and more than $98 \%$ of the viable $m d x ; I K K \beta^{F / F} ; M L C$-Cre litters were females, suggesting a sex bias in the segregation of these alleles Since expression of MLC-1f occurs early in skeletal muscle development $(32,33)$, it is possible that the requirement of IKK $\beta$ during embryonic development might be differentially regulated in a sex-specific manner in a dystrophic background. Based on these considerations, $m d x ; I K K \beta^{F / F} ; M L C$-Cre female mice were used for our analyses and were compared with age-matched $m d x ; I K K \beta^{F / F}$ female controls. Immunoblots confirmed that IKK $\beta$ was efficiently, but not completely, deleted in $m d x ; I K K \beta^{F / F} ; M L C$-Cre muscles (Figure 6A). 

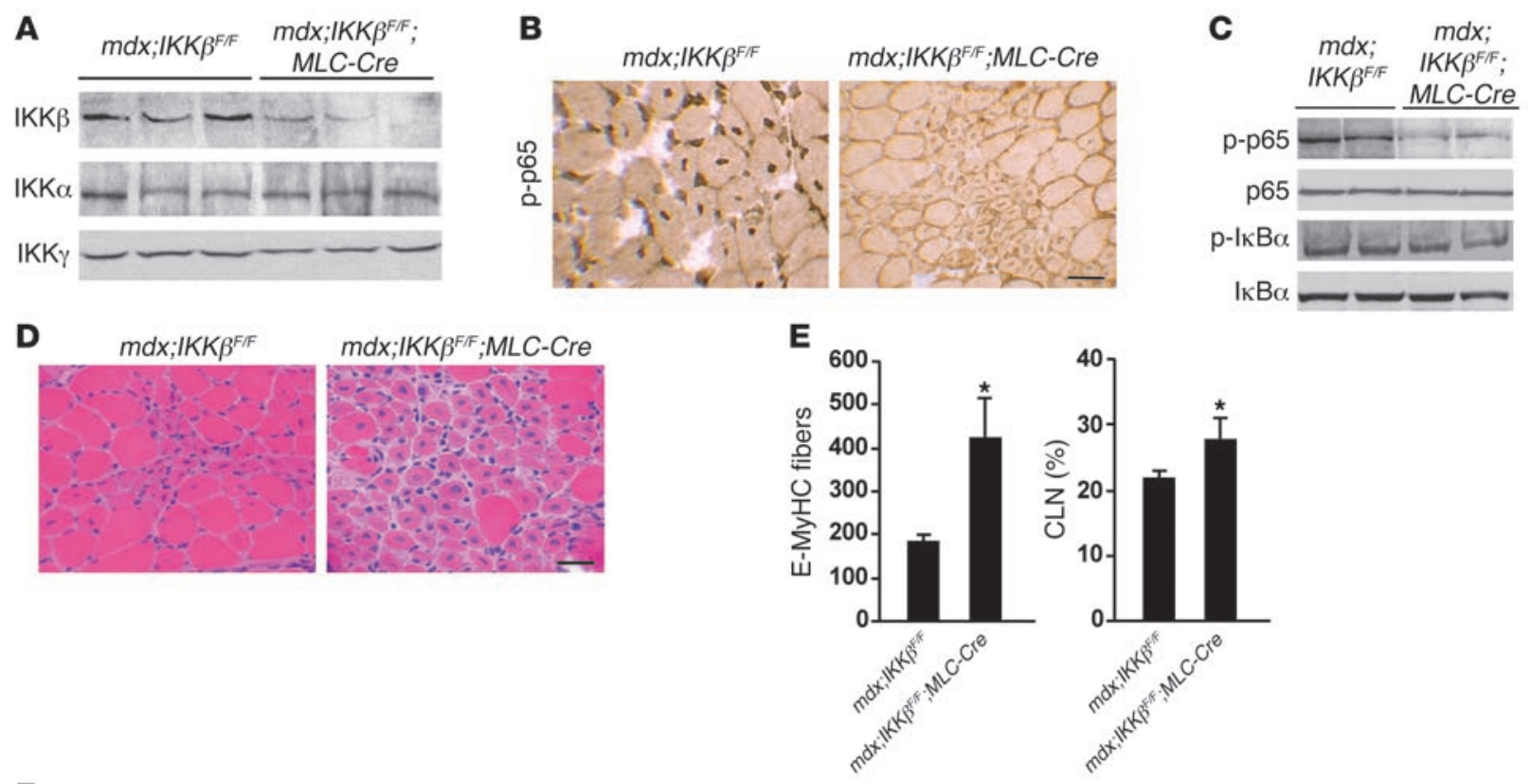

$\mathbf{F}$

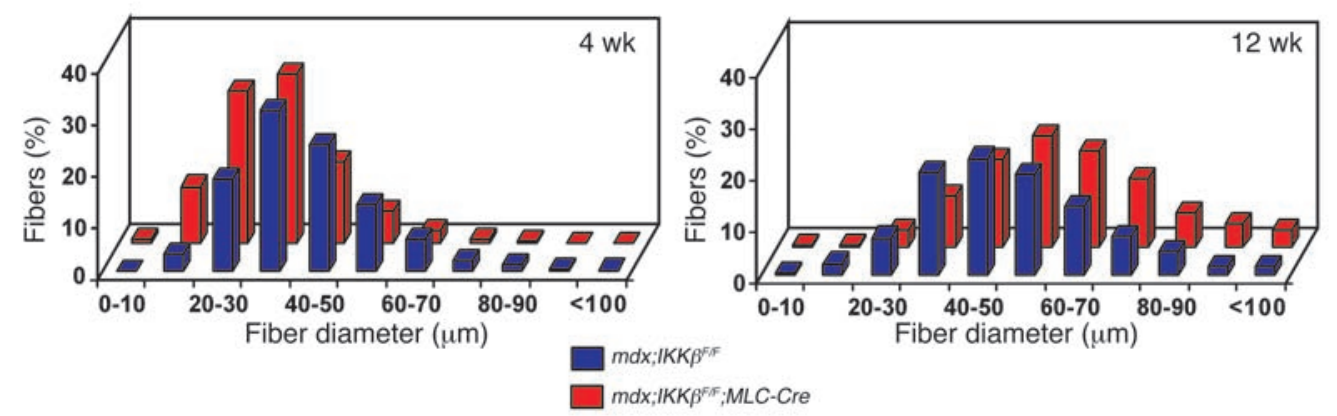

Figure 6

IKK $\beta$ deletion in muscle cells promotes regeneration. Muscles harvested from 4-week- $(\mathbf{A}-\mathbf{F})$ or 12 -week-old $\left(\mathbf{F}\right.$ only) $m d x$; IKK $\beta^{F / F}$ and $m d x ; I K K \beta^{F / F} ; M L C$-Cre mice were used for protein analysis (A and $\left.\mathbf{C}\right)$ or histology (B and $\left.\mathbf{D}\right)$. (A) Western blots probing for IKK subunits. (B) Muscles were immunostained for $\mathrm{p}$-p65 expression. (C) Western blots probing for $\mathrm{p}-\mathrm{p} 65, \mathrm{p} 65$, and IKB $\alpha$. (D) $\mathrm{H} \& \mathrm{E}$ staining of $m d x ; / K K \beta^{F / F}$ and $m d x ; I K K \beta^{F I F} ; M L C$-Cre muscles. (E) Muscles used in $\mathbf{D}$ were stained for quantitation of E-MyHC-positive stained fibers or stained with H\&E for counting of CLN. ${ }^{*} P<0.05$. Scale bars: $15 \mu \mathrm{m}(\mathbf{B})$ and $50 \mu \mathrm{m}$ (D). Graphs are plotted as mean \pm SEM. (F) Mean fiber distribution in $m d x ; / K K \beta^{F / F}$ and $m d x ; I K K \beta^{F / F} ; M L C$-Cre mice was determined from a minimum of 3,000 fibers from randomly chosen fields, obtained from multiple muscle sections from a minimum of 4 mice per group.

Nevertheless, reduction was sufficient to concomitantly decrease p-p65 specifically in regenerative fiber nuclei, without significantly affecting IKB phosphorylation or turnover (Figure 6, B and C). In addition, histological analysis of $m d x ; I K K \beta^{F / F} ; M L C$-Cre muscles revealed a noticeable increase in regeneration in muscles lacking IKK/NF- $\mathrm{KB}$ signaling (Figure 6D), which we quantitatively confirmed by E-MyHC staining (423.5 $\pm 91.72 \mathrm{E}-\mathrm{MyHC}$-positive stained fibers in $m d x ; I K K \beta^{F / F} ; M L C$-Cre mice compared with $182.29 \pm 15.79$ in $m d x ; I K K \beta^{F / F}$ mice; $\left.P=0.0008\right)$ and by scoring for centronucleated fibers $\left(27.63 \% \pm 3.48 \%\right.$ in $m d x ; I K K \beta^{F / F} ; M L C$-Cre mice compared with $21.72 \% \pm 1.21 \%$ in $m d x ; I K K \beta^{F / F}$ mice; $P=0.0358$ ) (Figure $6 \mathrm{E}$ and Supplemental Figure $3 \mathrm{~A}$ ). This analysis was performed at 4 weeks of age, when the regeneration phase in $m d x$ mice begins to peak. Morphometric measurements revealed that at this time, regenerative fibers in $m d x ; I K K \beta^{F / F} ; M L C$-Cre mice were smaller than those in $m d x ; I K K \beta^{F / F}$ mice. However, when fiber measurements were repeated at 12 weeks of age, fibers in $m d x ; I K K \beta^{F / F} ; M L C$-Cre muscles were found to be significantly larger (Figure 6F), suggesting that the higher regeneration capacity in $m d x ; I K K \beta^{F / F}$; $M L C$-Cre mice eventually culminated in more mature fiber formation. Taken together, these results support the existence of a pathway of IKK $\beta$-mediated NF-KB regulation in skeletal muscle that functions to inhibit regeneration in muscular dystrophy.

Muscle progenitor cells are increased in myofibers lacking IKK $\beta$ in dystrophic muscle. Since muscle repair is integrally linked to immune regulation (6), we considered the possibility that one mechanism by which loss of IKK $\beta / \mathrm{NF}-\kappa \mathrm{B}$ signaling in skeletal muscle could promote regeneration is through a concomitant reduction of immune modulators emanating from skeletal muscle tissue itself. However, histological analysis of $m d x ; I K K \beta^{F / F}$ and $m d x ; I K K \beta^{F / F} ; M L C-C r e$ muscles revealed no overt decreases in the number of immune cells, a finding that was confirmed by CD68 analysis (Figure 7A). Furthermore, while there was a reduction in TNF- $\alpha$ expression, no significant changes were seen in cytokine and chemokine genes IL-1 $\beta$, MCP-1, RANTES, and MIP- $1 \alpha$ (macrophage inflammatory protein $1 \alpha$ ) (Figure 7A), supporting the notion that muscle regen- 
A
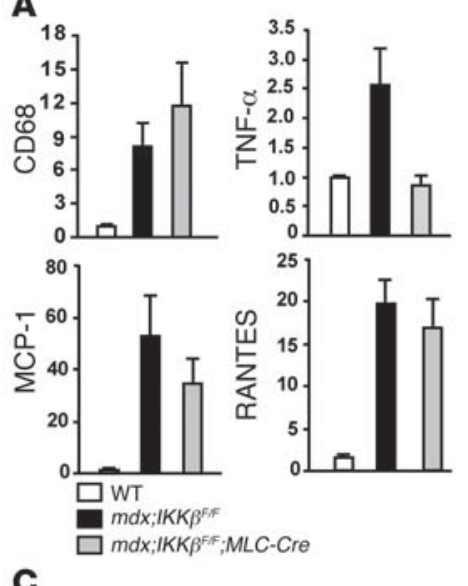

C

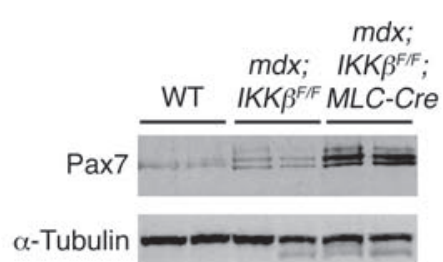

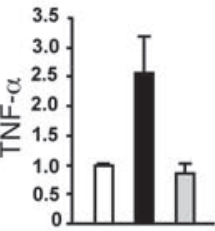
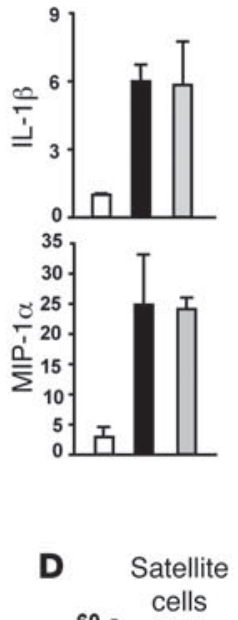

B
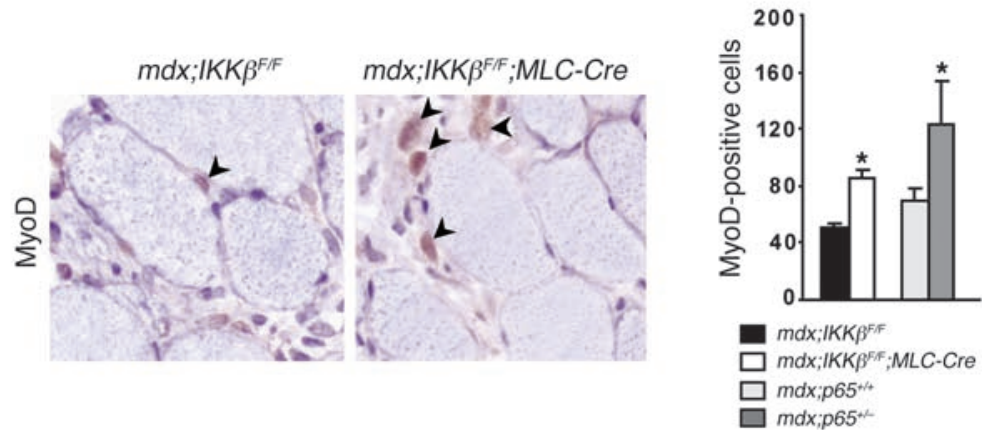

E Myotubes
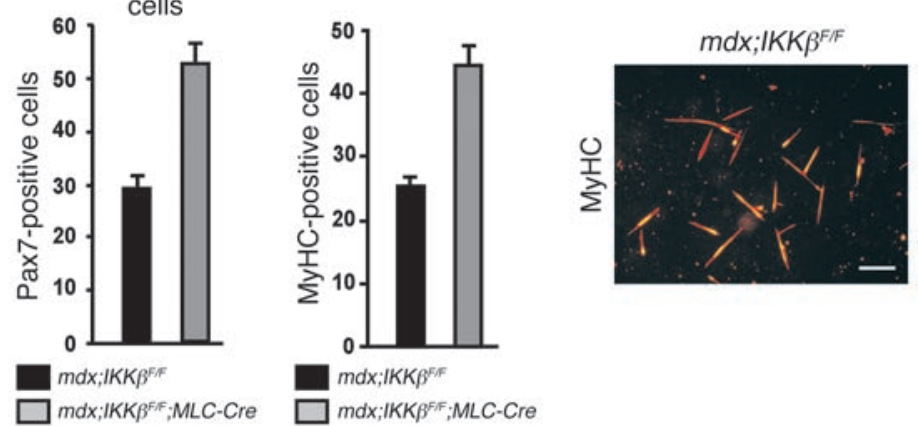

$m d x ; I K K \beta^{F / F} ; M L C-C r e$

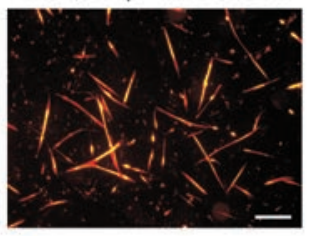

$\mathbf{F}$

$m d x ; I K K \beta^{\text {FIF }}$
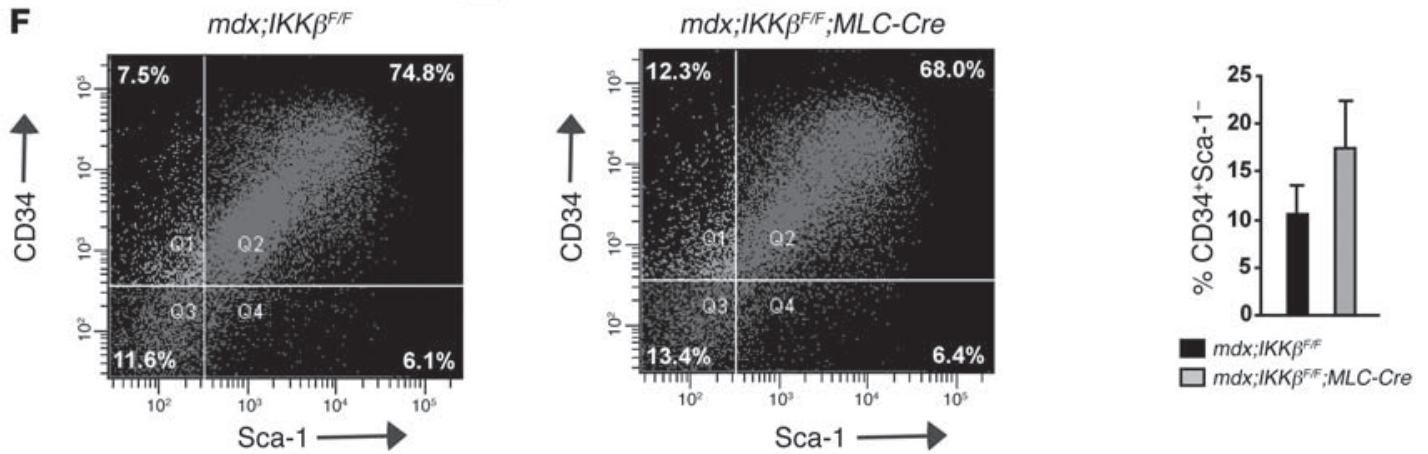

Figure 7

Muscle progenitor cells increase in mice lacking IKK $\beta$. Gastrocnemius or quadriceps were harvested from 4-week-old $m d x ; I K K \beta$ FIF and $m d x ; I K K \beta^{F I F} ; M L C$-Cre mice and frozen for RNA analysis (A), cryosectioned (B), or homogenized for immunoblotting (C). (A) Real-time PCR analysis of CD68, TNF- $\alpha$, IL-1 $\beta$, MCP-1, RANTES, and MIP-1 $\alpha$ (macrophage inflammatory protein $1 \alpha$ ) obtained from 3-6 mice per group. (B) Sections as described in $\mathbf{A}$ or from 7-week-old $m d x ; p 65^{+/+}$and $m d x ; p 65^{+/-}$mice were immunostained with MyoD and quantitated from a minimum of 20 randomly chosen fields per section in 3-4 animals per group. (C) Western blots probing for Pax7 and $\alpha$-tubulin. (D and E) Satellite cells were isolated from pooled hind limb muscles from 4-week-old $m d x ; I K K \beta F / F$ and $m d x ; / K K \beta F / F ; M L C$-Cre littermates and either fixed and stained with Pax7 or differentiated for 3 days and subsequently stained with MyHC to determine myotube number normalized per $\mathrm{mm}^{2}$ area. Scale bars: $200 \mu \mathrm{m}$. (F) Flow-cytometric analysis from freshly isolated cells of 4-week-old $m d x ; I K K \beta^{F / F}$ and $m d x ; / K K \beta^{F / F} ; M L C$-Cre mice were stained with cell-surface markers CD34 and Sca-1. Graph represents averages from 2 independent experiments. Data are plotted as mean \pm SEM.

eration due to a deletion of myofiber IKK $\beta / \mathrm{NF}-\mathrm{\kappa B}$ signaling is not primarily mediated by an attenuated immune response. Increased regeneration also did not correlate directly with the degree of muscle damage, since the percentage of necrosis did not significantly differ between $m d x ; I K K \beta^{F / F} ; M L C$-Cre and $m d x ; I K K \beta^{F / F}$ muscles (Supplemental Figure 3B).

Given that TNF- $\alpha$ expression was found to be lower in $m d x ; I K K \beta^{F / F} ; M L C$-Cre muscles and that this cytokine has been shown to inhibit myogenesis through the activation of NF- $\mathrm{KB}$ and the modulation of $\mathrm{MyoD}$ (34), we next considered that the ability of NF-KB to repress regeneration in dystrophic muscle might be linked to its negative regulation of the myogenic program. Indeed, assessment of $\mathrm{MyoD}$ by immunostaining revealed a $41 \%(P=0.0014)$ increase in $m d x ; I K K \beta^{F / F} ; M L C$-Cre compared with $m d x ; I K K \beta^{F / F}$ muscles, and similar results were found when $\mathrm{MyoD}$ levels were examined in $m d x ; p 65^{+/-}$mice (Figure 7B). These data support earlier in vitro findings (34) and suggest that increases in MyoD may be a contributing factor to the enhancement of myo- 
A

\begin{tabular}{|c|c|}
\hline QTE & WT) \\
\hline dia-TALDASAL & NBD (mut) \\
\hline
\end{tabular}

B
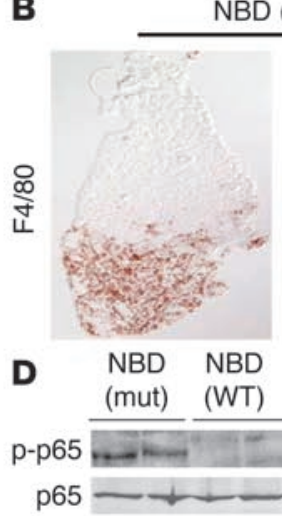

$p-\operatorname{l\kappa } B \alpha$

$1 \kappa \mathrm{Bc}$
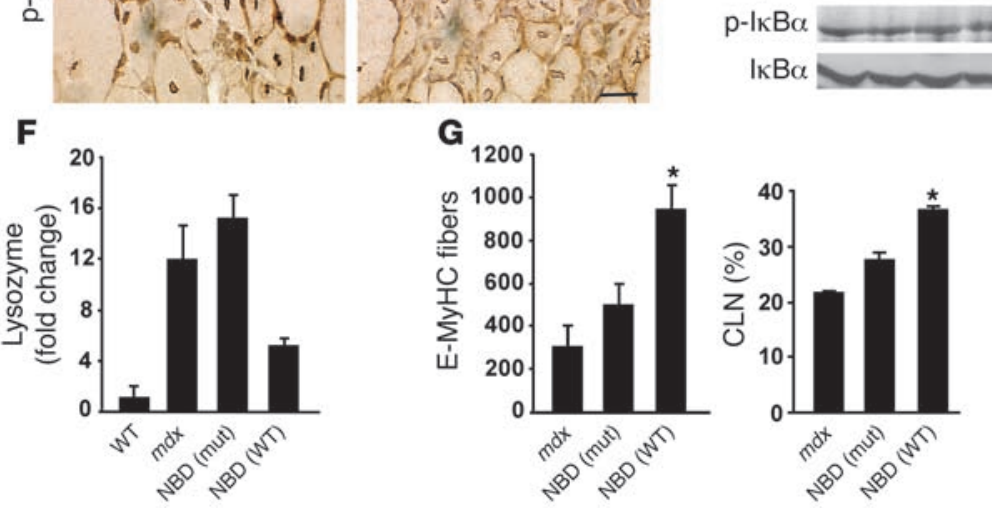

G

NBD (WT)
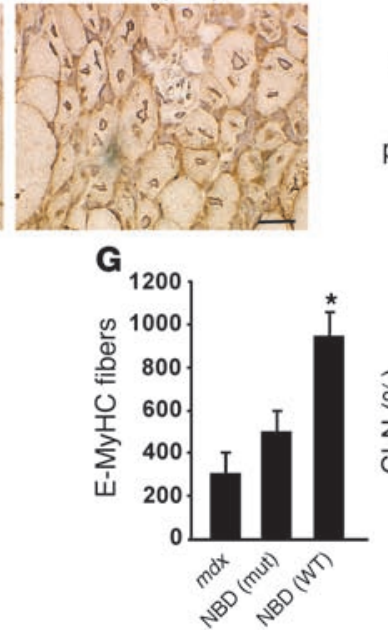

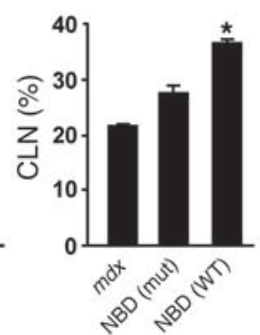

$\mathrm{BD}$ (mut)

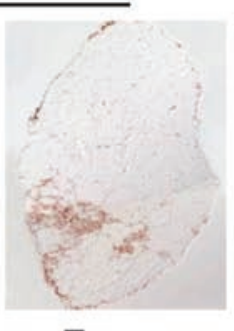

E

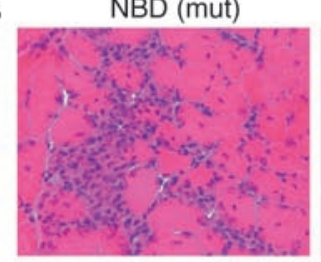

H

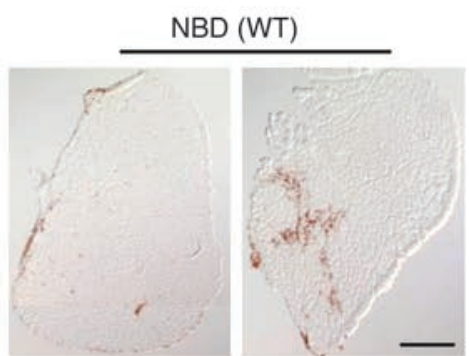

NBD (WT)
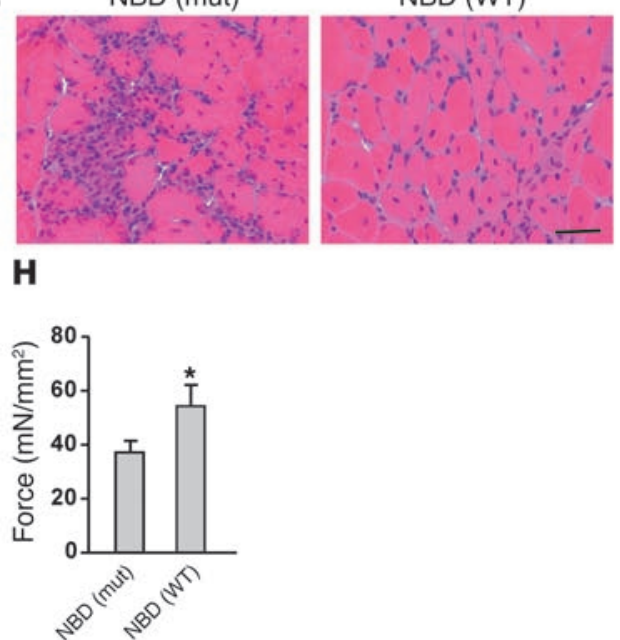

Figure 8

Pharmacological inhibition of IKK rescues the histopathology and function of dystrophic muscle. (A) Amino acid sequence of WT or mutant (mut) NBD peptides. Underlined amino acids indicate changes from WT to mutant forms. (B) Soleus muscles from WT or mutant NBD-treated mice were stained with F4/80, and macrophages were quantitated. Scale bar: $300 \mu \mathrm{m}$. (C) Gastrocnemius muscles harvested from mdx mice treated for 4 weeks were sectioned and stained with either p-p65 (C) or H\&E (E). Scale bars: $20 \mu \mathrm{m}$ (C and E). (D) Lysates from mice were used for Western blots probing for p-p65, p65, and IкB $\alpha$. (F) RNA was isolated from similar muscles as used for D including C57BL/10 and $m d x$ controls, and real-time PCR was performed for lysozyme $(n=4)$. (G) Regeneration potential was measured by quantitating fibers with centronucleation and positive E-MyHC staining from $m d x$ mice treated with saline or NBD peptides. (H) Force generation assessed by measuring active developed force comparing diaphragm muscles from mice treated with either WT or mutant NBD peptide for 4 weeks. Quantitative data are plotted as mean \pm SEM from 3 independent experiments. ${ }^{*} P<0.05$.

genesis in muscles lacking NF-кB signaling. Since expression of MyoD is represented in activated satellite cells committed to a myogenic lineage and differentiation in response to injury (27), we further speculated that NF- $\mathrm{KB}$ regulation of myogenesis might extend to the level of myogenic progenitors or satellite cells. By standard immunohistochemical stains, attempts to measure the satellite cell marker Pax7 were unsuccessful in determining specific nuclear reactivity, but immunoblotting detected an induction of Pax7 in $m d x$ muscles that was further increased in fibers lacking NF-кB (Figure 7C). Enhancement of Pax7 in $m d x ; I K K \beta^{F / F} ; M L C$-Cre muscles was substantiated when immunostaining was performed in freshly isolated satellite cells that were immediately fixed and quantitated following 2 short preplating steps to minimize fibroblast contamination (Figure 7D). Furthermore, satellite cultures prepared from $m d x ; I K K \beta^{F / F} ; M L C$-Cre muscles also led to a $43 \%$ increase in myotube formation $(P=0.0001)$ (Figure $7 \mathrm{E})$. This regulation of satellite cells was specific to the dystrophic condition, since $I K K \beta^{F / F} ; M L C$-Cre muscles on a WT background appeared indistinguishable from those of $I K K \beta^{F / F}$ or WT littermates, with no evidence of regeneration or Pax7 deregulation (Supplemental Figure 3, C and D).
Although the exact origin of satellite cells remains elusive, adult muscle-derived progenitor populations with stem cell-like properties that contribute to muscle formation during injury were recently identified $(35,36)$. To further assess the extent of regulation of the IKK/NF-кB signaling pathway in the satellite cell lineage during regenerative myogenesis, muscle progenitor populations from $m d x ; I K K \beta^{F / F} ; M L C$-Cre mice were isolated and analyzed by flow cytometry (Figure 7F). Combinatorial FACS analysis with CD34 and Sca-1 surface markers showed a 39\% higher proportion of CD34 $4^{+} \mathrm{Sca}-1^{-}$cells in $m d x ; I K K \beta^{F / F} ; M L C$-Cre mice compared with their $m d x ; I K K \beta^{F / F}$ littermates. Since the CD34+Sca-1- fraction of progenitor population isolated from adult muscles was found to display myogenic activity in vitro (Supplemental Figure 3F) as well as in vivo $(35,36)$, it is possible that increases in this fraction detected in $m d x$ muscles lacking NF- $\mathrm{KB}$ represent another source of enhanced regenerative potential. Collectively, these results indicate that chronic activation of IKK/NF- $\mathrm{KB}$ signaling in $m d x$ muscle contributes to dystrophic pathology through the negative regulation of an adult skeletal muscle progenitor cell population.

Pharmacological inbibition of IKK identifies the IKK/NF- $\mathrm{K} B$ signaling pathway as a therapentic target in muscular dystrophy. Our results from 
biochemical and genetic analyses implicate IKK/NF-кB signaling in the pathogenesis of DMD. To examine whether this signaling pathway is a target for DMD treatment, we utilized the cell-permeable NEMO-binding domain (NBD) peptide (Figure 8A), which was engineered from the $\mathrm{C}$ terminus of IKK $\beta$ and shown to function as a specific IKK inhibitor (37). In vivo, systemic administration of NBD peptide is not toxic in mice and inhibition of NF-KB correlates with attenuation of inflammatory response in other disease models (38). Indeed, treatment of prenecrotic 6-day-old $m d x$ mice with WT NBD peptide resulted in a significant mean decrease $(80 \% ; P=0.034)$ in macrophage infiltration in muscles as compared with similar administration with a mutant version of the peptide (Figure 8B). Consistent with the notion that macrophages promote inflammation-related membrane injury (6), decreased immune invasion was associated with a $77 \%$ reduction $(P=0.035)$ in membrane lysis with WT, but not mutant, NBD treatment (Supplemental Figure 4, A and B).

Next we asked whether NBD therapy would prove efficacious if treatment was pursued during the postnecrotic phase in $m d x$ mice. To this end, we began treatment from 23 days of age and continued for an additional 4 weeks. WT NBD but not mutant peptide treatment was successful in reducing NF-KB activity, as assessed by p-p65, which was again seen to be independent of I $\mathrm{B} \alpha$ turnover (Figure 8, C and D). Consistent with phenotypes from genetic ablations of p 65 and IKK $\beta$, treatment of $m d x$ mice with WT peptide caused a marked reduction in levels of immune infiltrates (Figure 8, E and F, and Supplemental Figure 4C). In contrast, only mild effects were observed in mutant NBD-treated compared with untreated $m d x$ mice. Furthermore, we addressed whether pharmacological inhibition of NF- $\kappa \mathrm{B}$ could promote muscle repair. Again, as seen with the genetic models, treatment of $m d x$ mice with WT NBD peptide increased the number of E-MyHC fibers by $47 \%$, with a smaller, but significant, increase of $24 \%$ in centronucleated fibers $(P=0.0007)$ (Figure $8 \mathrm{G})$.

A major consequence of the dystrophic process is the inability of degenerated muscles to produce a normal level of developed force in DMD patients (1), which is mimicked in diaphragm muscles from $m d x$ mice (39). Measurements of active force developed by diaphragm muscles from $m d x$ mice treated with WT NBD or mutant peptide were therefore performed in independent experiments in blinded fashion. Results revealed that diaphragm muscles from WT NBD-treated mice had significantly higher developed tetanic force $\left(54.0 \pm 7.8 \mathrm{mN} / \mathrm{mm}^{2} ; n=31\right)$ compared with mutant peptide-treated mice $\left(36.9 \pm 4.7 \mathrm{mN} / \mathrm{mm}^{2} ; n=22\right)$ $(P=0.048)$ (Figure $8 \mathrm{H})$, suggesting that restored muscle pathology and enhanced regeneration in mice treated with a specific IKK inhibitor correlated with improved muscle function. Taken together, these results elucidate that targeting the IKK/NF-KB signaling pathway could be of clinical relevance in muscular dystrophies, specifically in improving the secondary pathology that is critical to the disease progression of DMD.

\section{Discussion}

The data presented here provide genetic evidence supporting the role of IKK/NF-кB in the pathogenesis of muscular dystrophy and mark this signaling pathway as a potential therapeutic target for the management of DMD. Our results are consistent with previous studies $(16,17)$ in describing the activation of NF-KB in dystrophic muscles; however, in contrast to the earlier studies, we find this activity to be associated with both immune cells and regenerative

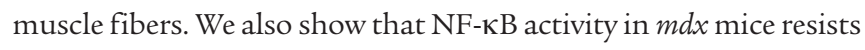
the normal downregulation seen during postnatal development in WT mice. Because this activation coincides with the initiating phases of $m d x$ pathology, we suspect that inflammatory signals are likely to be involved in this regulation. Another distinguishing feature of our study is the presence of chronic NF- $\kappa \mathrm{B}$ activity without evidence of classical IкB $\alpha$ phosphorylation and turnover. In fact, the data instead point to elevated IKK activity that activates p65 transcriptional activity through phosphorylation of serine 536 . Although in our hands EMSAs revealed predominant p50 binding in dystrophic muscles, unlike in disuse atrophy $(14,15)$, genetic analysis did not support the involvement of this subunit in $m d x$ pathology. Studies utilizing homozygous p50 mutant mice will be needed to substantiate the role of p50 in dystrophic muscles.

One of the mechanisms by which IKK/NF- $\kappa$ B signaling appears to contribute to dystrophy is by promoting chronic inflammation. Due to the wide range of $\mathrm{NF}-\mathrm{KB}$ target genes, including cytokines and chemokines (9), we speculate that NF-кB-mediated transcription might serve as an amplification signal for persistent immune response in dystrophic muscle. In effect, the reduction in inflammatory response in $m d x$ mice with heterozygous deletion of p 65 , myeloid-specific deletion of IKK $\beta$, or treatment with NBD peptide supports such a notion. Besides immune cells, injured muscle fibers also act as sources of cytokines and chemokines involved in immune cell chemotaxis (6). However, dystrophic muscles lacking IKK $\beta$ showed levels of macrophages similar to those in control $m d x$ mice, suggesting that IKK $\beta$ function in muscle cells is not likely to involve a chemotactic response. Nevertheless, the regulation of TNF- $\alpha$ detected from both IKK $\beta$ deleted myeloid and muscle cells supports the hypothesis that the decrease in inflammation observed in $p 65^{+/-}$and NBD-treated mice could result from an impaired inflammatory signaling loop between muscle fibers and immune cells. It is also possible that the activation of NF- $\kappa \mathrm{B}$ emanating from other immune compartments such as mast and T cells $(6,10)$ might contribute to the inflammatory processes in dystrophic muscles.

A second mechanism by which IKK/NF- $\mathrm{KB}$ signaling regulates the dystrophic process is repression of muscle regeneration. The findings in this study suggest that blocking NF-кB function either genetically or by pharmacological means promotes formation of new myofibers in response to degeneration. These results are highly consistent with recent evidence that IKK deletion in muscles in response to acute injury can also lead to increased regeneration (40). Muscle regeneration after injury represents a coordinated sequence of events involving the activation of quiescent satellite cells into myoblasts and their subsequent fusion to newly formed myotubes (27). NF- $\kappa \mathrm{B}$ has been previously shown to repress the differentiation program by targeting MyoD (34) and by preventing myoblast fusion in vitro (41). Our current in vivo study is consistent with previous in vitro findings that TNF- $\alpha$ inhibits myogenesis through repression of MyoD (34). Importantly, the data also reveal a new mechanism by which the NF- $\mathrm{KB}$ signaling pathway regulates the early initiating steps of regenerative myogenesis by modulating progenitor cell number in dystrophic muscles, although exactly how NF- $\mathrm{BB}$ mediates this action on the progenitor population, satellite cells, or myoblasts during regeneration remains to be further explored. However, based on our results, it is tempting to speculate that NF- $\mathrm{KB}$ signaling from damaged myofibers could potentially limit the activation of progenitor populations and interfere with their participation in repair. 
Importantly, since satellite cells are exhausted very early due to futile rounds of degeneration and regeneration cycles in muscles of DMD patients $(1,4)$, any pharmacological agent that blocks $\mathrm{NF}-\kappa \mathrm{B}$ and maintains or replenishes the progenitor population even partially could possibly improve muscle pathology and function. Furthermore, if NF-кB inhibition in the early stages of dystrophy can reduce the inflammation burden, this might in turn slow the initial exhaustion of the regenerative capacity in dystrophic muscles. Sustained inhibition of IKK/NF-KB signaling could in turn allow dystrophic muscles to recuperate and reinitiate muscle repair in the later phases of the disease. Since NF-кB regulation maintains a delicate balance between cell survival and apoptosis and is very important for host defense mechanisms, the specificity and duration of the NF- $\mathrm{KB}$-inhibiting agent becomes highly relevant in designing effective pharmacological therapies against chronic diseases. Whereas IKK $\beta$ inhibition in macrophages is beneficial in reducing inflammation in cancer (42), IKK $\alpha$ loss in macrophages can actually elevate the immune response by increasing the production of proinflammatory cytokines and chemokines (43), thus underscoring the importance of specificity for IKK inhibitors. Similarly, though administration of nonspecific agents such as MG-132 (44) and, more recently, a synthetic antioxidant (45), has been shown to ameliorate the dystrophic phenotype, risks of inhibiting unwanted cellular targets can also sometimes outweigh the benefits (46). In addition, our inability to detect clear evidence of IкB $\alpha$ degradation in dystrophic muscles may argue against the use of general proteasome inhibitors as a therapeutic strategy for blocking classical NF- $\mathrm{KB}$ signaling in DMD. Hence, the implementation of a specific NF- $\mathrm{KB}$ inhibitor such as the NBD peptide might provide maximal therapeutic benefit with minimal side effects (47). Although long-term inhibition of NF- $\mathrm{\kappa B}$ is associated with a vulnerability to bacterial infections and mounting immune responses (48), it is noteworthy that the NBD peptide has not been found to block basal NF-KB activity (37) and, as seen in this and previously described studies, does not exhibit overt signs of toxicity $(38,47)$. Together, the results identify the IKK/NF-KB signaling pathway as a viable target for anti-DMD therapy.

\section{Methods}

Mice. $m d x\left(\mathrm{C} 57 \mathrm{BL} / 10 \mathrm{ScSn} \mathrm{DMD}^{\mathrm{mdx}}\right), \mathrm{NF}_{-} \kappa \mathrm{B1}^{+/-}, \mathrm{TNFa}^{-/}$, and Lys-Cre mice were purchased from The Jackson Laboratory and NF-KB reporter mice from Xenogen. All genotypes were determined by PCR analysis from tail DNA. Mice were housed in the animal facilities of The Ohio State University Comprehensive Cancer Center under conventional conditions with constant temperature and humidity and fed a standard diet. Animal experimentation was approved by The Ohio State University Animal Care and Use Committee. For cardiotoxin experiments, $100 \mu \mathrm{l}$ of $10 \mu \mathrm{M}$ cardiotoxin dissolved in PBS was injected into the TA of either $p 65^{+/+}$or $p 65^{+/-}$mice. NBD peptide synthesis is described in the Supplemental material. Peptide injections were performed using 2 regimens in independent laboratories. In one group of male $m d x$ mice, peptides were injected intraperitoneally, beginning at 6 days of age, daily for 22 days at $10 \mathrm{mg} / \mathrm{kg}$. In a second group, peptides were injected intraperitoneally at $200 \mu \mathrm{g}$ per mouse, beginning at 23 days of age, once every 3 days for 27 days.

Patients. DMD muscle biopsies were obtained in accordance with the Institutional Review Boards of Columbus Children's Research Institute after informed consent.

Histology. Frozen muscle sections were stained as previously described (49). For immunostaining, p-p65 antibodies (either unconjugated or Alexa Fluor 488 conjugated) (1:500; Cell Signaling Technology), p65
(1:5,000; Rockland), luciferase (1:1,000; Sigma-Aldrich), MyoD (1:50; Dako), F4/80 (1:500; Serotec), E-MyHC (1:50; Developmental Studies Hybridoma Bank, University of Iowa, Iowa City, Iowa, USA), CD68 (1:500; Serotec), IKK $\beta$ (1:50; Imgenex), or MyHC (1:500, Sigma-Aldrich) were used. Immunofluorescence of cultured cells with E-MyHC (1:50) and Pax7 (1:100) (Developmental Studies Hybridoma Bank) was used. Rhodamine- and Oregon green-conjugated secondary antibodies (1:250; Molecular Probes; Invitrogen) were used for indirect immunofluorescence, and Hoescht stain (1:10,000; Sigma-Aldrich) was used for nuclear detection. For E-MyHC and centronucleation quantitation, counts were performed from a minimum of 20 randomly chosen fields, from 5-6 sections throughout the length of the muscle in 4-6 animals per group. Calcifications were identified by von Kossa and H\&E staining (49), and staining of muscle sections for cytoplasmic IgG accumulation was performed as previously described (50). Fiber diameter measurements were determined as reported previously (49).

Satellite cell isolation. Total hind limb muscles (3 mice per group) were digested with type II collagenase (Worthington Biochemical Corp.) and dispase (Roche Diagnostics) for 70 minutes, and cell suspensions were then preplated for an hour in tissue culture flasks containing supplemented DMEM media as previously described (51). Nonadherent cells were centrifuged, counted, and labeled with biotin-conjugated CD34, clone RAM 34 (eBiosciences). Negative control staining was performed with the omission of the primary antibody. Cells were then incubated with anti-biotin paramagnetic beads and selected using a MiniMACS separation system according to the manufacturer's instructions (Miltenyi Biotec). Cells were subsequently labeled with streptavidin coupled to PE (BD Biosciences - Pharmingen) and then incubated with FITC-conjugated Sca-1 antibody (clone D7; BD Biosciences - Pharmingen) for flow cytometry analysis (FACSAria cytometer using FACSDiva software; BD Biosciences). Sorted gates were defined based on isotype controls and single stained cells, and sorted cells were differentiated as described previously (52). Satellite cells were isolated as described previously $(53,54)$.

Functional analysis. Diaphragm muscles were rapidly excised and placed in ice-cold standard Krebs-Henseleit solution. Diaphragm strips (0.9 $\pm 0.03 \mathrm{~mm}$ wide; $1-4$ strips per mouse) were mounted between a force transducer (KG-7; Scientific Instruments) and a micromanipulator device in the experimental setup. The muscle was allowed to stabilize at $37^{\circ} \mathrm{C}$ in Krebs-Henseleit solution with constant oxygenation. Following delivery of a monophasic stimulus to the muscle, the voltage was gradually increased until all motor units were activated. Subsequently, the muscle was slowly stretched to determine the optimal length. The muscle was then rested for 5 minutes before the tetanic protocol was started. Maximal tetanic contraction was assessed at $250 \mathrm{~Hz}$ for a $600-\mathrm{ms}$ duration. In addition, to investigate a potentially different frequency response between groups, tetani were assessed by sequential stimulation at 20,50, $80,120,150,200$, and $250 \mathrm{~Hz}$ with 2 minutes rest in between. The crosssectional area for each muscle was determined by dividing muscle weight by its length and tissue density, and muscle force was compared after correction for cross-sectional area.

EMSA and reporter assays. EMSA and supershift analyses were performed on whole muscles as previously described (49). The antibody against p65 was obtained from Rockland and antibodies against p50, c-Rel, RelB, Bcl-3, and p52 from Santa Cruz Biotechnology Inc. For reporter assays, tissue homogenates were prepared in M-PER (Pierce), and standard luciferase assays were performed.

Western blotting, kinase assays, and real-time PCR. Muscle extracts for Western blot analysis were prepared as previously described (52) and probed using antibodies against p-p65, p-IкB, pIKK (1:500; Cell Signaling Technology), IкB $\alpha$ (1:500; Santa Cruz Biotechnology Inc.), IKK $\alpha$ (1:500; Imgenex), IKK $\beta$ 
(1:500; Cell Signaling Technology), IKK $\gamma$ (1:500; Santa Cruz Biotechnology Inc.) and p65 (1:10,000; Rockland). IKK assays were performed according to published procedures $(14,31)$ with the exception that IKK $\gamma$ was used to immunoprecipitate endogenous IKK. For real-time analysis, RNA was isolated from muscle tissues, and real-time PCR was performed as described previously (49) using primers listed in the Supplemental material.

Statistics. All quantitative data are represented as mean \pm SEM unless otherwise noted. Analysis was performed between different groups using 2-tailed Student's $t$ test and nonparametric Mann-Whitney $U$ test. Statistical significance was set at $P<0.05$.

\section{Acknowledgments}

We thank the members of the Guttridge laboratory, especially J. Wang, K. Ladner, and E. Hertlein, for discussions and technical advice. Special thanks go to S. Burden for MLC-Cre mice; M. Mayo for GST-p65 constructs; J. Mendell for helpful suggestions;
B. McElwain for flow cytometry advice; M. Ostrowski and G. Leone for reagents; and A. Asakura for critical technical input. We also thank G. Wei, G. Lesinsky, W. Chen, T. Zabuawala, R. Opavsky, P. Trikha, J. Stein, K. Kigerl, and E. McDaniel for helpful reagents and R. Jain for critical review of the manuscript. Work was supported by NIH grants AI35098 (to A.S. Baldwin) and CA098466 (to D.C. Guttridge), and the Muscular Dystrophy Association (to D.C. Guttridge).

Received for publication October 5, 2006, and accepted in revised form February 6, 2007.

Address correspondence to: Denis C. Guttridge, The Ohio State University College of Medicine, $420 \mathrm{~W}$. 12th Avenue, Columbus, Ohio 43210, USA. Phone: (614) 688-3137; Fax: (614) 688-4006; E-mail: denis.guttridge@osumc.edu.
1. Blake, D.J., Weir, A., Newey, S.E., and Davies, K.E. 2002. Function and genetics of dystrophin and dystrophin-related proteins in muscle. Physiol. Rev. 82:291-329.

2. Emery, A.E. 2002. The muscular dystrophies. Lancet. 359:687-695.

3. Dalkilic, I., and Kunkel, L.M. 2003. Muscular dystrophies: genes to pathogenesis. Curr. Opin. Genet. Dev. 13:231-238.

4. Durbeej, M., and Campbell, K.P. 2002. Muscular dystrophies involving the dystrophin-glycoprotein complex: an overview of current mouse models. Curr. Opin. Genet. Dev. 12:349-361.

5. Gorospe, J.R., Tharp, M.D., Hinckley, J., Kornegay, J.N., and Hoffman, E.P. 1994. A role for mast cells in the progression of Duchenne muscular dystrophy? Correlations in dystrophin-deficient humans, dogs, and mice. J. Neurol. Sci. 122:44-56.

6. Tidball, J.G. 2005. Inflammatory processes in muscle injury and repair. Am. J. Physiol. Regul. Integr. Comp. Physiol. 288:R345-R353.

7. Porreca, E., et al. 1999. Haemostatic abnormalities, cardiac involvement and serum tumor necrosis factor levels in X-linked dystrophic patients. Thromb. Haemost. 81:543-546.

8. Porter, J.D., et al. 2002. A chronic inflammatory response dominates the skeletal muscle molecular signature in dystrophin-deficient mdx mice. Hum. Mol. Genet. 11:263-272.

9. Hayden, M.S., and Ghosh, S. 2004. Signaling to NF-kappaB. Genes Dev. 18:2195-2224.

10. Li, Q., Withoff, S., and Verma, I.M. 2005. Inflammation-associated cancer: NF-kappaB is the lynchpin. Trends Immunol. 26:318-325.

11. Karin, M., and Ben-Neriah, Y. 2000. Phosphorylation meets ubiquitination: the control of NF-kap$\mathrm{paB}$ activity. Annu. Rev. Immunol. 18:621-663.

12. Baldwin, A.S., Jr. 2001. Series introduction: the transcription factor NF- $\kappa \mathrm{B}$ and human disease. J. Clin. Invest. 107:3-6.

13. Karin, M., Cao, Y., Greten, F.R., and Li, Z.W. 2002. NF-kappaB in cancer: from innocent bystander to major culprit. Nat. Rev. Cancer. 2:301-310.

14. Cai, D., et al. 2004. IKKbeta/NF-kappaB activation causes severe muscle wasting in mice. Cell. 119:285-298.

15. Hunter, R.B., and Kandarian, S.C. 2004. Disruption of either the $N f k b 1$ or the $B c l 3$ gene inhibits skeletal muscle atrophy. J. Clin. Invest. 114:1504-1511. doi:10.1172/JCI200421696.

16. Baghdiguian, S., et al. 1999. Calpain 3 deficiency is associated with myonuclear apoptosis and profound perturbation of the IkappaB alpha/NF-kap$\mathrm{paB}$ pathway in limb-girdle muscular dystrophy type 2A. Nat. Med. 5:503-511.

17. Monici, M.C., Aguennouz, M., Mazzeo, A., Messina,
C., and Vita, G. 2003. Activation of nuclear factorkappaB in inflammatory myopathies and Duchenne muscular dystrophy. Neurology. 60:993-997.

18. Kumar, A., and Boriek, A.M. 2003. Mechanical stress activates the nuclear factor-kappaB pathway in skeletal muscle fibers: a possible role in Duchenne muscular dystrophy. FASEB J. 17:386-396.

19. Deconinck, A.E., et al. 1997. Utrophin-dystrophindeficient mice as a model for Duchenne muscular dystrophy. Cell. 90:717-727.

20. Sasaki, C.Y., Barberi, T.J., Ghosh, P., and Longo, D.L. 2005. Phosphorylation of RelA/p65 on serine 536 defines an IkappaBalpha-independent NFkappaB pathway. J. Biol. Chem. 280:34538-34547.

21. Carlsen, H., Moskaug, J.O., Fromm, S.H., and Blomhoff, R. 2002. In vivo imaging of NF-kappa B activity. J. Immunol. 168:1441-1446.

22. Beg, A.A., Sha, W.C., Bronson, R.T., Ghosh, S., and Baltimore, D. 1995. Embryonic lethality and liver degeneration in mice lacking the RelA component of NF-kappa B. Nature. 376:167-170.

23. Sha, W.C., Liou, H.C., Tuomanen, E.I., and Baltimore, D. 1995. Targeted disruption of the p50 subunit of NF-kappa B leads to multifocal defects in immune responses. Cell. 80:321-330.

24. Doi, T.S., et al. 1999. Absence of tumor necrosis factor rescues RelA-deficient mice from embryonic lethality. Proc. Natl. Acad. Sci. U. S. A. 96:2994-2999.

25. Spencer, M.J., Marino, M.W., and Winckler, W.M. 2000. Altered pathological progression of diaphragm and quadriceps muscle in TNF-deficient, dystrophin-deficient mice. Neuromuscul. Disord. 10:612-619.

26. Khurana, T.S., and Davies, K.E. 2003. Pharmacological strategies for muscular dystrophy. Nat. Rev. Drug Discov. 2:379-390.

27. Charge, S.B., and Rudnicki, M.A. 2004. Cellular and molecular regulation of muscle regeneration. Physiol. Rev. 84:209-238.

28. Guttridge, D.C., Albanese, C., Reuther, J.Y., Pestell, R.G., and Baldwin, A.S., Jr. 1999. NF-kappaB controls cell growth and differentiation through transcriptional regulation of cyclin D1. Mol. Cell. Biol. 19:5785-5799.

29. Li, Z.W., Omori, S.A., Labuda, T., Karin, M., and Rickert, R.C. 2003. IKK beta is required for peripheral B cell survival and proliferation. J. Immunol. 170:4630-4637.

30. Clausen, B.E., Burkhardt, C., Reith, W., Renkawitz, R., and Forster, I. 1999. Conditional gene targeting in macrophages and granulocytes using LysMcre mice. Transgenic Res. 8:265-277.

31. Sakurai, H., Chiba, H., Miyoshi, H., Sugita, T., and Toriumi, W. 1999. IkappaB kinases phosphorylate NF-kappaB p 65 subunit on serine 536 in the transactivation domain. J. Biol. Chem. 274:30353-30356.
32. Bothe, G.W., Haspel, J.A., Smith, C.L., Wiener, H.H., and Burden, S.J. 2000. Selective expression of Cre recombinase in skeletal muscle fibers. Genesis. 26:165-166.

33. Jiang, P., et al. 2002. Targeted deletion of the MLC1f/3f downstream enhancer results in precocious MLC expression and mesoderm ablation. Dev. Biol. 243:281-293.

34. Guttridge, D.C., Mayo, M.W., Madrid, L.V., Wang, C.Y., and Baldwin, A.S., Jr. 2000. NF-kappaB-induced loss of MyoD messenger RNA: possible role in muscle decay and cachexia. Science. 289:2363-2366.

35. Sherwood, R.I., et al. 2004. Isolation of adult mouse myogenic progenitors: functional heterogeneity of cells within and engrafting skeletal muscle. Cell. 119:543-554.

36. Montarras, D., et al. 2005. Direct isolation of satellite cells for skeletal muscle regeneration. Science. 309:2064-2067.

37. May, M.J., et al. 2000. Selective inhibition of NFkappaB activation by a peptide that blocks the interaction of NEMO with the IkappaB kinase complex. Science. 289:1550-1554.

38. di Meglio, P., Ianaro, A., and Ghosh, S. 2005. Amelioration of acute inflammation by systemic administration of a cell-permeable peptide inhibitor of NF-kappaB activation. Arthritis Rheum. 52:951-958.

39. Lynch, G.S., et al. 1997. Contractile properties of diaphragm muscle segments from old $\mathrm{mdx}$ and old transgenic mdx mice. Am. J. Physiol. 272:C2063-C2068.

40. Mourkioti, F., et al. 2006. Targeted ablation of IKK2 improves skeletal muscle strength, maintains mass, and promotes regeneration. J. Clin. Invest. 116:2945-2954. doi:10.1172/JCI28721.

41. Thaloor, D., Miller, K.J., Gephart, J., Mitchell, P.O., and Pavlath, G.K. 1999. Systemic administration of the NF-kappaB inhibitor curcumin stimulates muscle regeneration after traumatic injury. Am. J. Physiol. 277:C320-C329.

42. Greten, F.R., et al. 2004. IKKbeta links inflammation and tumorigenesis in a mouse model of colitis-associated cancer. Cell. 118:285-296.

43. Li, Q., et al. 2005. Enhanced NF-kappaB activation and cellular function in macrophages lacking IkappaB kinase 1 (IKK1). Proc. Natl. Acad. Sci. U. S. A. 102:12425-12430.

44. Bonuccelli, G., et al. 2003. Proteasome inhibitor (MG-132) treatment of $\mathrm{mdx}$ mice rescues the expression and membrane localization of dystrophin and dystrophin-associated proteins. Am.J. Pathol. 163:1663-1675.

45. Messina, S., et al. 2006. Nuclear factor kappa-B blockade reduces skeletal muscle degeneration 
and enhances muscle function in Mdx mice. Exp. Neurol. 198:234-241.

46. Sprong, R.C., et al. 1998. Low-dose N-acetylcysteine protects rats against endotoxin-mediated oxidative stress, but high-dose increases mortality. Am. J. Respir. Crit. Care Med. 157:1283-1293.

47. Jimi, E., et al. 2004. Selective inhibition of NFkappa B blocks osteoclastogenesis and prevents inflammatory bone destruction in vivo. Nat. Med. 10:617-624.

48. Lavon, I., et al. 2000. High susceptibility to bacterial infection, but no liver dysfunction, in mice compromised for hepatocyte NF-kappaB activation.
Nat. Med. 6:573-577.

49. Acharyya, S., et al. 2005. Dystrophin glycoprotein complex dysfunction: a regulatory link between muscular dystrophy and cancer cachexia. Cancer Cell. 8:421-432.

50. Straub, V., Rafael, J.A., Chamberlain, J.S., and Campbell, K.P. 1997. Animal models for muscular dystrophy show different patterns of sarcolemmal disruption. J. Cell Biol. 139:375-385.

51. Jankowski, R.J., Haluszczak, C., Trucco, M., and Huard, J. 2001. Flow cytometric characterization of myogenic cell populations obtained via the preplate technique: potential for rapid isolation of muscle- derived stem cells. Hum. Gene Ther. 12:619-628.

52. Acharyya, S., et al. 2004. Cancer cachexia is regulated by selective targeting of skeletal muscle gene products. J. Clin. Invest. 114:370-378. doi:10.1172/ JCI200420174.

53. Rando, T.A., and Blau, H.M. 1994. Primary mouse myoblast purification, characterization, and transplantation for cell-mediated gene therapy. J. Cell Biol. 125:1275-1287.

54. Asakura, A., Komaki, M., and Rudnicki, M. 2001. Muscle satellite cells are multipotential stem cells that exhibit myogenic, osteogenic, and adipogenic differentiation. Differentiation. 68:245-253. 